US Army Corps

of Engineers

Waterways Experiment

Station

Coastal Inlets Research Program

\title{
Wave Breaking on a Current at an Idealized Inlet; Coastal Inlets Research Program, Inlet Laboratory Investigations
}

by Jane M. Smith, William C. Seabergh, Gordon S. Harkins, Michael J. Briggs

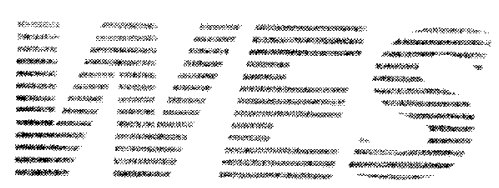

Approved For Public Release; Distribution Is Unlimited

Prepared for Headquarters, U.S. Army Corps of Engineers 
The contents of this report are not to be used for advertising, publication, or promotional purposes. Citation of trade names does not constitute an official endorsement or approval of the use of such commercial products.

The findings of this report are not to be construed as an official Department of the Army position, unless so designated by other authorized documents. 


\section{Wave Breaking on a Current at an Idealized Inlet; Coastal Inlets Research Program, Inlet Laboratory Investigations}

by Jane M. Smith, William C. Seabergh, Gordon S. Harkins, Michael J. Briggs

U.S. Army Corps of Engineers Waterways Experiment Station 3909 Halls Ferry Road

Vicksburg, MS 39180-6199

Final report

Approved for public release; distribution is unlimited

Prepared for U.S. Army Corps of Engineers

Washington, DC 20314-1000

Under Inlet Laboratory Investigations Work Unit 32935 


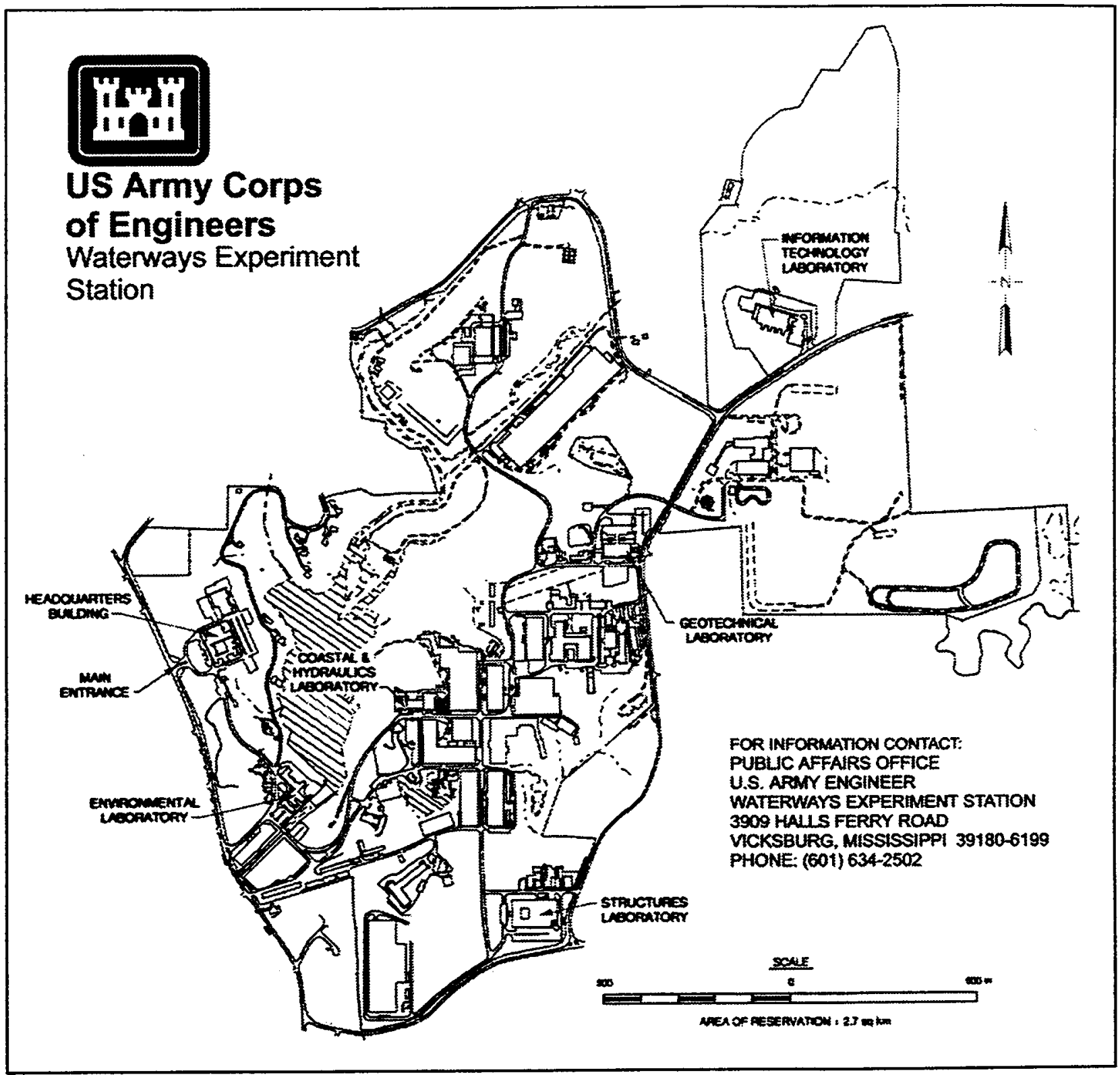

Waterways Experiment Station Cataloging-in-Publication Data

Wave breaking on a current at an idealized inlet : Coastal Inlets Research Program, inlet laboratory investigations / by Jane M. Smith ... [et al.] ; prepared for U.S. Army Corps of Engineers.

57 p. : ill. ; 28 cm. - (Technical report ; CHL-98-31)

Includes bibliographic references.

1. Water waves. 2. Ocean currents. 3. Inlets. I. Smith, Jane M. II. United States. Army. Corps of Engineers. III. U.S. Army Engineer Waterways Experiment Station. IV. Coastal and Hydraulics Laboratory (U.S. Army Engineer Waterways Experiment Station) V. Coastal Inlets Research Program (U.S.) VI. Series: Technical report (U.S. Army Engineer Waterways Experiment Station) ; CHL-98-31.

TA7 W34 no.CHL-98-31 


\section{Contents}

Preface $\ldots \ldots \ldots \ldots \ldots \ldots \ldots \ldots \ldots \ldots \ldots \ldots$

Conversion Factors, Non-SI to SI Units of Measurement $\ldots \ldots \ldots \ldots$ vii

1 -Introduction $\ldots \ldots \ldots \ldots \ldots \ldots \ldots \ldots \ldots \ldots \ldots$

Background $\ldots \ldots \ldots \ldots \ldots \ldots \ldots \ldots \ldots \ldots \ldots \ldots \ldots$

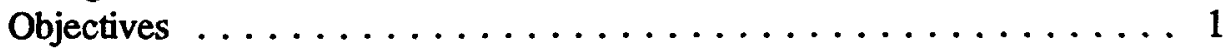

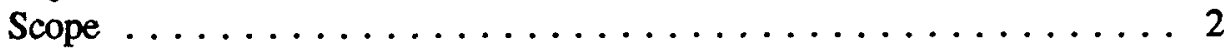

2-Experiment Arrangement $\ldots \ldots \ldots \ldots \ldots \ldots \ldots$

Idealized Inlet Facility $\ldots \ldots \ldots \ldots \ldots \ldots \ldots$

Instrumentation and Calibration $\ldots \ldots \ldots \ldots \ldots \ldots \ldots$

Experiment Series ...................

3-Experiment Procedures and Data Analysis ............. 9

Sequence of Events and Data Sampling . . . . . . . . . . 9

Data Analysis . . . . . . . . . . . . . . . . . . 9

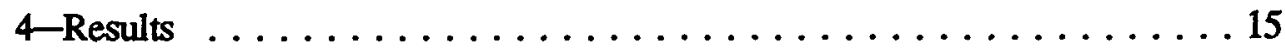

1-D Wave-Current Interaction $\ldots \ldots \ldots \ldots \ldots \ldots \ldots \ldots$

Breaking Formulations $\ldots \ldots \ldots \ldots \ldots \ldots \ldots \ldots$

Spectra . . . . . . . . . . . . . . . . . . 18

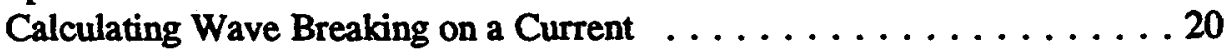

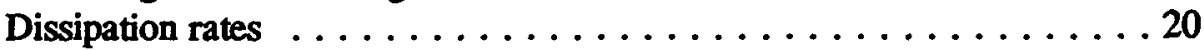

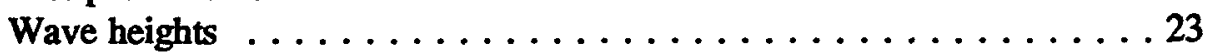

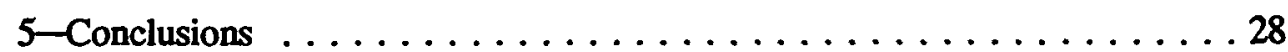

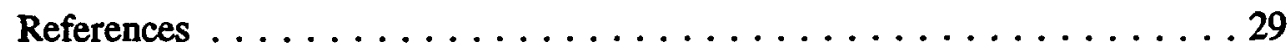

Photos 1-6 
Appendix A: Data Tables $\ldots \ldots \ldots \ldots \ldots \ldots \ldots \ldots \ldots$ A1

Appendix B: Spectra Plots $\ldots \ldots \ldots \ldots \ldots \ldots \ldots \ldots \ldots$ B1

Appendix $\mathrm{C}:$ Notation $\ldots \ldots \ldots \ldots \ldots \ldots \ldots \ldots \ldots$

SF 298 


\section{Preface}

The research investigation described herein was conducted as part of the Coastal Inlets Research Program (CIRP) under the work unit "Inlet Laboratory Investigations." Overall program management for CIRP is directed by the Hydraulic Design Section of Headquarters, U.S. Army Corps of Engineers (HQUSACE). Program Monitors for the CIRP at HQUSACE are

Messrs. Barry W. Holliday, John Bianco, and Charles B. Chesnutt. The Program Manager is Mr. E. Clark McNair, Coastal and Hydraulics Laboratory (CHL), U.S. Army Engineer Waterways Experiment Station (WES), and CIRP Technical Manager is Dr. Nicholas C. Kraus, CHL.

The mission of the CIRP is to conduct applied research to improve USACE's capability to manage federally maintained inlets which exist on all coasts of the United States (including Atlantic, Gulf, Pacific, and the Great Lakes regions). Objectives are to (a) make management of channels -design, maintenance, and operation-more effective to reduce the cost of dredging, and (b) preserve the adjacent beaches in a systems approach that treats the inlet and beach together. To achieve the above objectives, CIRP includes work units on short-wave modeling, circulation modeling, channels and adjacent shorelines, inlet scour, laboratory investigations, field investigations, and technology transfer.

The study was conducted by CHL personnel, under the general direction of Dr. James R. Houston, Director, and Mr. Charles C. Calhoun, Jr., Assistant Director, CHL. Direct guidance was provided by Messrs. C. E. Chatham, Chief, Navigation and Harbors Division, and Dennis Markle, Chief, Harbors and Entrances Branch, CHL. Experiments were conducted by Messrs. William Henderson, Computer Assistant, Cecil Dorrell, and Hugh F. Acuff, Jr., Civil Engineering Technicians, under the direction of Mr. William C. Seabergh, Principal Investigator, Dr. Jane M. Smith, and Messrs. Gordon S. Harkins and Michael J. Briggs, all of CHL. Messrs. Wallace Guy and David Daily of the WES Information Technology Laboratory provided instrumentation support. This report was prepared by Dr. Smith and Messrs. Seabergh, Harkins, and Briggs. Word Processing and formatting were completed by Ms. Myra E. Willis, CHL. 
At the time this study was conducted, Director of WES was Dr. Robert W. Whalin. Commanders were initially COL Bruce K. Howard, EN, followed by COL Robin R. Cababa, EN.

The contents of this report are not to be used for advertising, publication, or promotional purposes. Citation of trade names does not constitute an official endorsement or approval of the use of such commercial products. 


\section{Conversion Factors, Non-SI to SI Units of Measurement}

Non-SI units of measurement used in this report can be converted to SI units as follows:

\begin{tabular}{||l|l|l|}
\hline Multiply & By & To Obtain \\
\hline degrees (angle) & 0.01745329 & radians \\
\hline feet & 0.3048 & meters \\
\hline gallons & 3.785 & liters \\
\hline
\end{tabular}




\section{Introduction}

Waves in tidal inlets steepen and break on strong ebb currents. Although wave breaking at inlet entrances impacts navigation, sediment transport, and wave penetration into the inlet, the wave breaking process in the presence of a current is poorly understood.

\section{Background}

Previous laboratory studies of wave breaking on a current include Hedges, Anastasion, and Gabriel (1985); Lai, Long, and Huang (1989); and Suh, Kim, and Lee (1994). Hedges, Anastasion, and Gabriel developed a limiting spectral shape for waves breaking on a current in deep water and tested it with four spectra in a wave-current flume. Suh, Kim, and Lee extended the Hedges, Anastasion, and Gabriel formula to finite water depths and tested it with nine spectra in a flume. In both studies, little of the data is presented, and results are given in the form of limiting spectra. Lai, Long, and Huang performed a detailed flume experiment of wave-current interaction kinematics in deep water. They observed that linear theory predicted kinematics well, if the Doppler shift is included; they confirmed deep-water blocking of waves if the ratio of ebb current velocity to wave celerity exceeded 0.25 ; and they observed a downshifting of the peak wave frequency for breaking on a strong current. Ris and Holtuijsen (1996) used Lai, Long, and Huang's deepwater breaking data to evaluate breaking criteria and found that the whitecapping formulation of Komen, Hasselmann, and Hasselmann (1984) under-estimated dissipation. Supplementing this whitecapping with the Battjes and Janssen (1978) breaking algorithm gave significantly better agreement with the data. In this study, we will evaluate dissipation formulations with a new data set that includes shallow to intermediate relative water depths.

\section{Objectives}

In this report, wave breaking on a current is examined through physical-model measurements in an idealized inlet with a steady ebb current. Wave and current measurements are used to evaluate wave dissipation models. The goal of the study is to determine a dissipation function for wave breaking on a current that is based on integrated wave parameters, is applicable for arbitrary water depths, and is robust. 


\section{Scope}

This introduction described candidate wave dissipation formulations and selected previous studies of wave breaking on a current. The experiment arrangement (including the laboratory facility, the instrumentation, and the experimental series) and experiment procedures and data analysis (including sequence of events, calibration, sampling, data analysis methods, data format, and example plots) are presented in Chapters 2 and 3 . Trends in the measured spectra, evaluation and development of dissipation formulations, and application of the formulations to calculate wave height decay are presented under "Results" in Chapter 4. In Chapter 5, conclusions are summarized. 


\section{Experiment Arrangement}

As part of the Coastal Inlets Research Program, a physical model facility was created to address research and field problems of tidal inlets. This tool and appurtenances necessary to study inlet problems are discussed in this chapter.

\section{Idealized Inlet Facility}

An idealized inlet was designed to fit in a 46-m- (150-ft)- wide by $99-\mathrm{m}$ (325-ft)- long concrete basin with $0.6-\mathrm{m}-(2-\mathrm{ft})$ - high walls. ${ }^{1}$ The approach was to design an inlet with simplified bathymetry and fairly steep beach slopes so that additional features (such as an ebb shoal) could easily be added. Also, it was anticipated that a fine sand would be used as both a tracer and as a fully mobile bed, which could be placed over the concrete bottom in a thick veneer. A 1:50 undistorted scale was assumed to determine reasonable inlet dimensions to model. However, other scales can easily be assumed to accommodate the study of specific processes due to the simplified bathymetry.

Figure 1 shows the basin area. The ocean-side parallel contours were determined by using an equilibrium profile equation from Dean (1977)

$$
h=A x^{0.67}
$$

where $h$ is the stillwater depth, $x$ is distance offshore, and $A$ is determined by the sediment grain size. ${ }^{2}$ A value of 0.24 was used, as it represented a relatively steep beach. The contoured ocean beach slope extends to the $18.3-\mathrm{cm}(0.6-\mathrm{ft})$ mean low water (mlw) depth (or the 9.1-m (30-ft) depth when scaled by 1:50) and is then linearly transitioned to the basin floor at a depth of $30.4 \mathrm{~cm}(1.0 \mathrm{ft})$ (or $15.2 \mathrm{~m}(50 \mathrm{ft})$ ) when scaled by 1:50). The inlet throat region converges to a depth of $15.2 \mathrm{~cm}$ (or scaled to $1: 50,7.6 \mathrm{~m}(25 \mathrm{ft})$ ) relative to a mlw datum. The minimum width is $244 \mathrm{~cm}$ across the inlet between mlw contours (or when scaled by $1: 50$, it represents a width of $122 \mathrm{~m}(400 \mathrm{ft})$ ). Figure 2 shows the inlet throat and entrance channel with parallel jetties which have a spacing of $3.66 \mathrm{~m}$

\footnotetext{
${ }^{1}$ A table of factors for converting non-SI units of measurement to SI units can be found on page vii.

${ }^{2}$ For convenience, symbols and abbreviations are listed in the notation (Appendix C).
} 


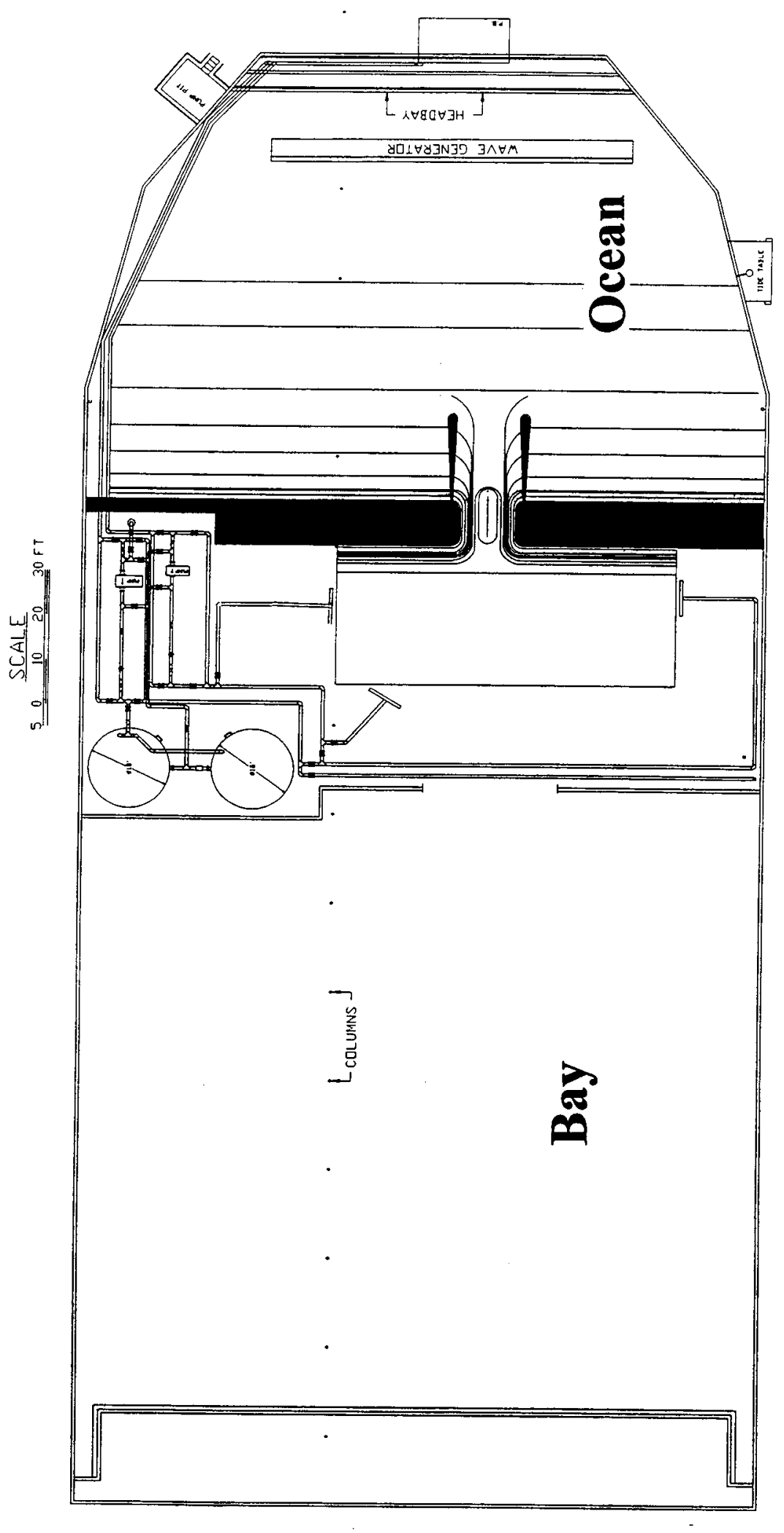

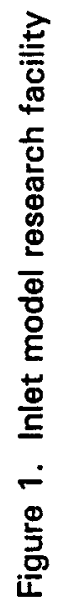




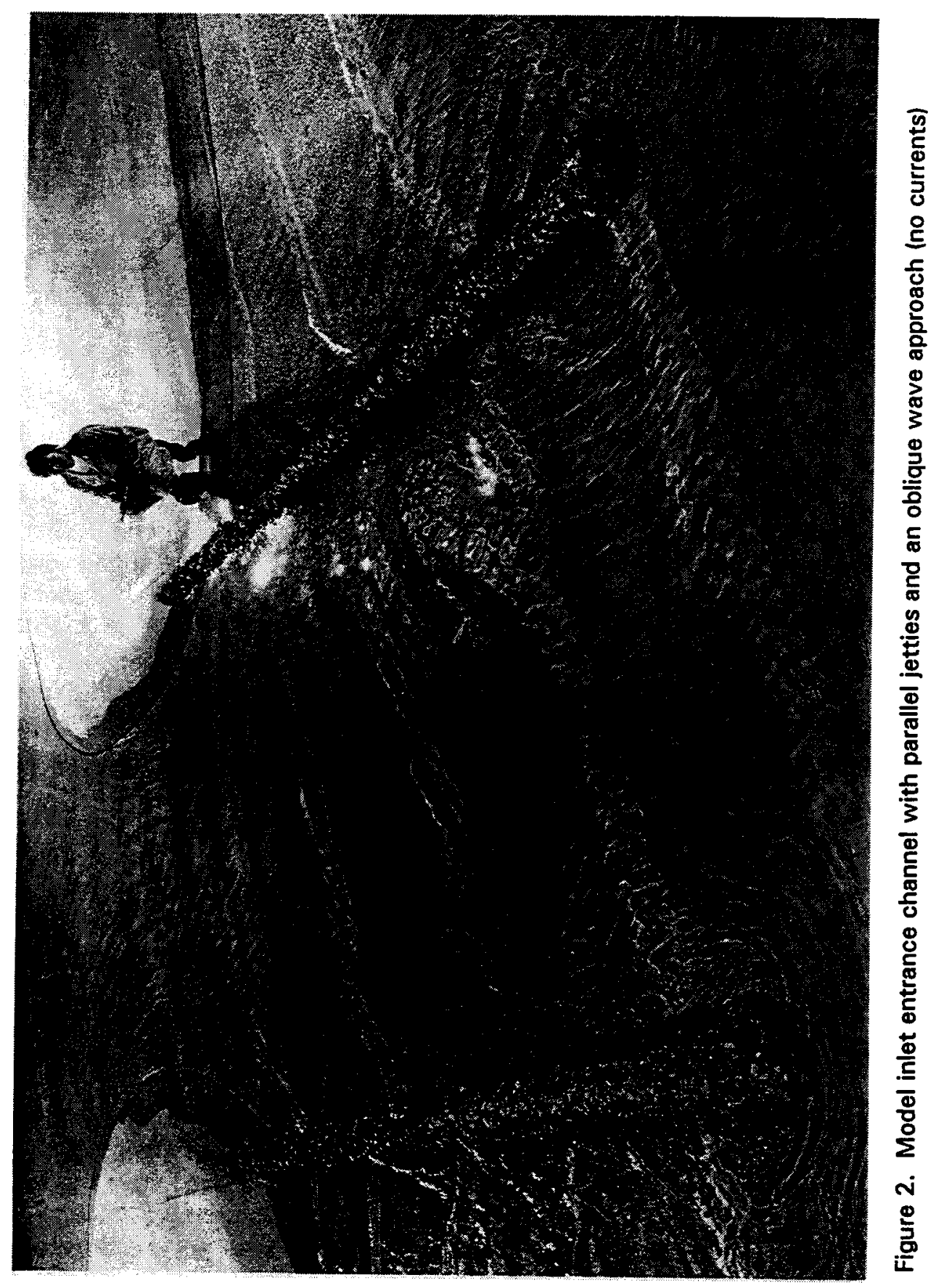


$(12.0 \mathrm{ft}$ ) and extend $5.5 \mathrm{~m}(18 \mathrm{ft})$ offshore (or when scaled to 1:50, spacing of $183 \mathrm{~m}(600 \mathrm{ft})$, extending $275 \mathrm{~m}$ (900 ft) offshore.

Based on Froude's model law (Stevens 1942) and the linear scale of 1:50, the model-prototype relations in Table 1 were derived. Dimensions are in terms of length $(l)$ and time $(t)$.

\begin{tabular}{||l|l|l||}
\hline \begin{tabular}{l}
$\mid \begin{array}{l}\text { Table } 1 \\
\text { Model-Prototype Scale Relations at 1:50 Undistorted Scale }\end{array}$ \\
\hline Charactoristic
\end{tabular} & Dimension & $\begin{array}{l}\text { Model-Prototype } \\
\text { Scale Relation }\end{array}$ \\
\hline Length & $t$ & $I_{r}=1: 50$ \\
\hline Area & $F$ & $A_{r}=I_{r}^{2}=1: 2,500$ \\
\hline Volume & $\beta$ & $V_{r}=I_{r}^{3}=1: 125,000$ \\
\hline $\begin{array}{l}\text { Time (tidal and short wave } \\
\text { period) }\end{array}$ & $t$ & $t_{r}=\sqrt{r}=1: 7.07$ \\
\hline Velocity & $/ / t$ & $v=/ / t_{r}=1: 10$ \\
\hline
\end{tabular}

Other scales may be assumed for the bathymetry, so the different scaling relationships seen in Table 1 would apply.

The Idealized Inlet Facility is connected to a large sump (volume of $1.98 \times 10^{\circ} \ell$ $(523,000 \mathrm{gal})$ ) for water exchange so that tides may be produced in the facility's ocean to drive tidal currents into and out of the inlet bay. A constant inflow is introduced from the sump into the model ocean while a "rolling" gate either reduces or increases flow area over an exit pipe into the sump, which causes ocean rise or fall, respectively. The rolling gate is regulated by a controller connected to a feedback loop comparing actual to desired water level. The two circular shapes in Figure 1 are storage tanks each holding $182,000 \ell(48,000 \mathrm{gal})$ water. They can be used to simulate a much larger bay area by storing flood tide water and releasing it back to the bay to flow to the ocean during ebb flow. Pumps and control valves associated with this procedure are located adjacent to the storage tanks.

A steady-state flow may also be established for ebbing or flooding currents. The piping system is shown in Figure 1. Water is either collected (flood flow) or distributed (ebb flow) through a system of manifolds in the bay which may be adjusted for 1,2 , or 3 bay channels or a uniform flow across the bay. Water is either released (flood flow) or taken from (ebb flow) the ocean headbay to complete the circulation which is energized by the pumps located in the upper left corner of Figure 1.

Either irregular or monochromatic waves were produced by an 80 -ft-long, unidirectional plunge-type (vertical motion) wave generator (see Figure 1). Unscaled wave periods could be varied from 0.5 to about $3 \mathrm{~s}$ and wave heights to $10 \mathrm{~cm}$ (at the generator location and for this particular arrangement of the generator). Wave angle could be varied for specific tests by moving the generator on its castors. 


\section{Instrumentation and Calibration}

Wave data were collected with electrical capacitance wave gauges which were calibrated daily with a computer-controlled procedure incorporating a least-square fit of measurements at 11 steps. This averaging technique, using 21 voltage samples per gauge, minimizes the effects of slack in the gear drives and hysteresis in the sensors. Typical calibration errors are less than 1 percent of full scale for the capacitance wave gauges. Wave signal generation and data acquisition were controlled using a DEC MicroVax I computer. Wave data were analyzed with a DEC VAX 3600.

Water velocity data were collected with Sontek 2D Acoustic Doppler Velocimeters with a side-looking probe which is oriented to collect information on the two velocity components in the horizontal plane. Samples were collected at $10 \mathrm{~Hz}$, though the instrument makes 250 pings per second and averages for each output sample. Accuracy is \pm 0.5 percent of the measured velocity, with resolution of $0.1 \mathrm{~mm} / \mathrm{s}$ and threshold of $0.1 \mathrm{~cm} / \mathrm{s}$. The probe samples a $0.25-\mathrm{cm}^{3}$ volume located $5 \mathrm{~cm}$ from the sensor heads.

The sensors were placed as seen in Figure 3. An offshore array of wave gauges in front of the wave generator measured the waves outside the region of currents. In the inlet region a gauge rack was designed to hold both the wave and current meters in a colinear manner, with a $0.61-\mathrm{m}$ (2.0-ft) separation between alternating sensors. The rack was then moved to other locations for test reruns of the same wave and current condition to complete a data set.

\section{Experiment Series}

Wave conditions for the study were zero-moment wave height $H_{m o}=3.7$ and $5.5 \mathrm{~cm}$, peak spectral period $T_{p}=0.7$ and $1.4 \mathrm{~s}$, and incident wave direction perpendicular to the jetties and at 20 deg relative to the jetties. All waves were generated with a TMA spectral form using a gamma value of 3.30. The current velocities were 0,12 , and $24 \mathrm{~cm} / \mathrm{s}$ as determined fom a reference gauge located in the center of the channel seaward of the inlet gorge but between the jetties. Magnitude of the current decreased approximately 20 percent seaward of the jetties (between current meters 3 and 1). Twelve runs were analyzed for the work presented here (two periods, two heights, three current speeds, and normal wave incidence). Wave parameters considered in this study are summarized in Table 2 (lab and prototype scale), where $U$ is the average current magnitude, $C$ is the wave celerity, and $k$ is wave number. Table 2 gives the target incident wave conditions and maximum current in the inlet throat. The wave and current parameters cover a wide range of values, which makes the data useful to evaluate the wave dissipation formulations for current-induced wave breaking. Each experiment run was repeated three times, first with the wave gauge and current meter array centered between the jetties and then offset to the left and to the right of the center line by $1 \mathrm{~m}$. Waves and currents at the three positions across the channel were similar and were averaged. 


\begin{tabular}{|l|l|l|l|l|l|l|l|l||}
\hline \hline Table 2. Laboratory Wave Parameters \\
\hline \hline Scale & $H_{m o}$ & $T_{p}$ & $U$ & $H_{m o} / L$ & $U / C$ & $H_{m o} / d$ & $k d$ & $k H_{m o} / 2$ \\
\hline \hline Lab & $3.7,5.5 \mathrm{~cm}$ & $0.7,1.4 \mathrm{~s}$ & $\begin{array}{l}0,14,24 \\
\mathrm{~cm}\end{array}$ & $\begin{array}{l}0.025- \\
0.11\end{array}$ & $\begin{array}{l}0- \\
0.45\end{array}$ & $\begin{array}{l}0.25- \\
0.63\end{array}$ & $\begin{array}{l}0.4- \\
1.4\end{array}$ & $\begin{array}{l}0.07- \\
0.3\end{array}$ \\
\hline $\begin{array}{l}\text { Prototype } \\
1: 50\end{array}$ & $1.85,2.75 \mathrm{~m}$ & $4.9,9.9 \mathrm{~s}$ & $\begin{array}{l}0.10,1.7 \\
\mathrm{~m} / \mathrm{s}\end{array}$ & $\begin{array}{l}0.025- \\
0.11\end{array}$ & $\begin{array}{l}0- \\
0.45\end{array}$ & $\begin{array}{l}0.25- \\
0.63\end{array}$ & $\begin{array}{l}0.4- \\
1.4\end{array}$ & $\begin{array}{l}0.07- \\
0.3\end{array}$ \\
\hline
\end{tabular}

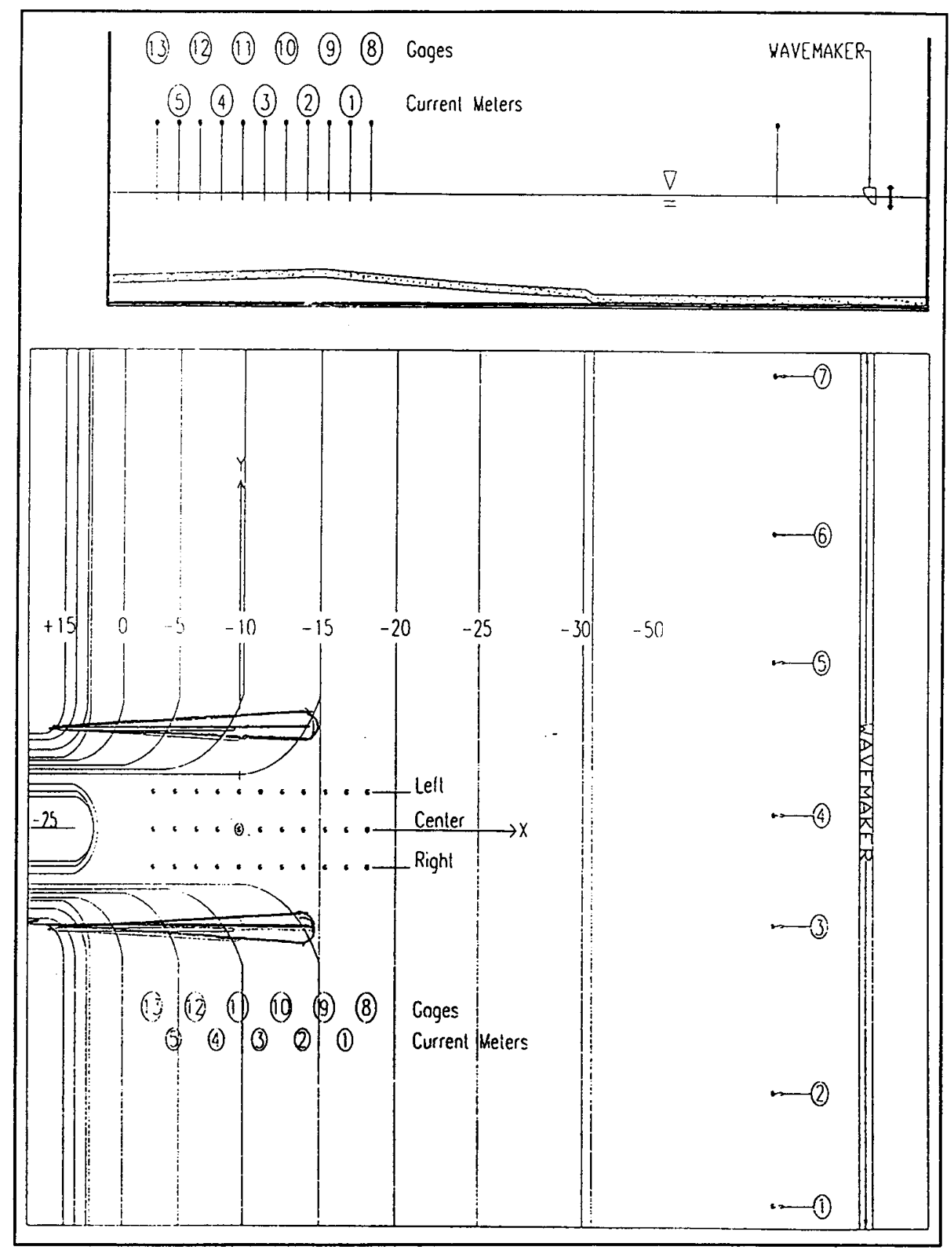

Figure 3. Wave and current meter gauge locations 


\section{Experiment Procedures and Data Analysis}

This chapter provides information on data collection and analysis. Some selected sample plots of data are shown.

\section{Sequence of Events and Data Sampling}

Following daily calibration of the wave gauges (Chapter 2), the ebb flow was first set in the proper range using a flowmeter installed in the pipeline downstream of the pump location. The flow setting then was refined by bringing the current to its proper level by using a reference current meter in the inlet channel. With a stable flow in the channel, current velocities were collected at all locations for about $70 \mathrm{~s}$ (700 data samples), then the wave generator was turned on and both current and wave data were collected. The wave generator was operated for $1,020 \mathrm{~s}$. Wave gauge sampling rate was $20 \mathrm{~Hz}$, so 20,400 water elevation data points were collected at each gauge and 10,200 velocity data samples $(10-\mathrm{Hz}$ sampling rate) for each sensor were collected during a run.

Figure 4 compares target and measured spectra at a wave gauge location in front of the wave generator. Figure 5 is a snapshot of waves over a portion of an experiment at some of the gauges, first for a waves-only experiment test (upper two panels), and then a wave-current experiment (lower 2 panels).

\section{Data Analysis}

The velocity data were analyzed in the time domain. The pre-wave velocity record was averaged over the initial 700 samples. Velocity records after the wave generator was in operation were examined individually to determine when a steady-state average was reached and a long-as-possible record was averaged, usually on the order of 8,000 to 9,000 samples (up to $900 \mathrm{~s}$ of data). Figure 6 shows the currents at stations for a particular run. Initially, there is steady state flow without waves, then once wave activity has begun, there is a transitory period for the adjustment to a near steady state with oscillations superimposed due to wave orbital velocities. 


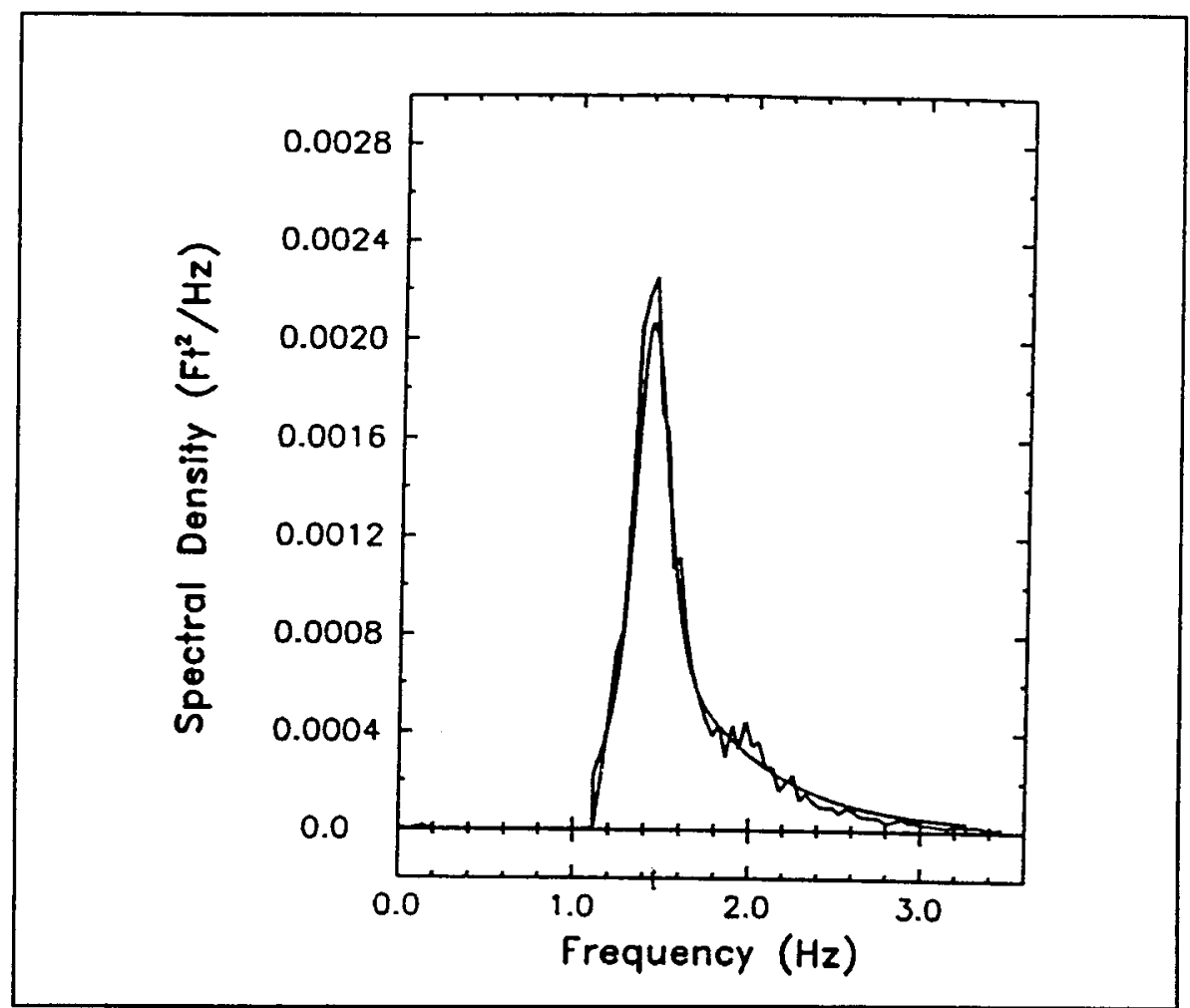

Figure 4. Comparison of target and measured spectra for wave generation 


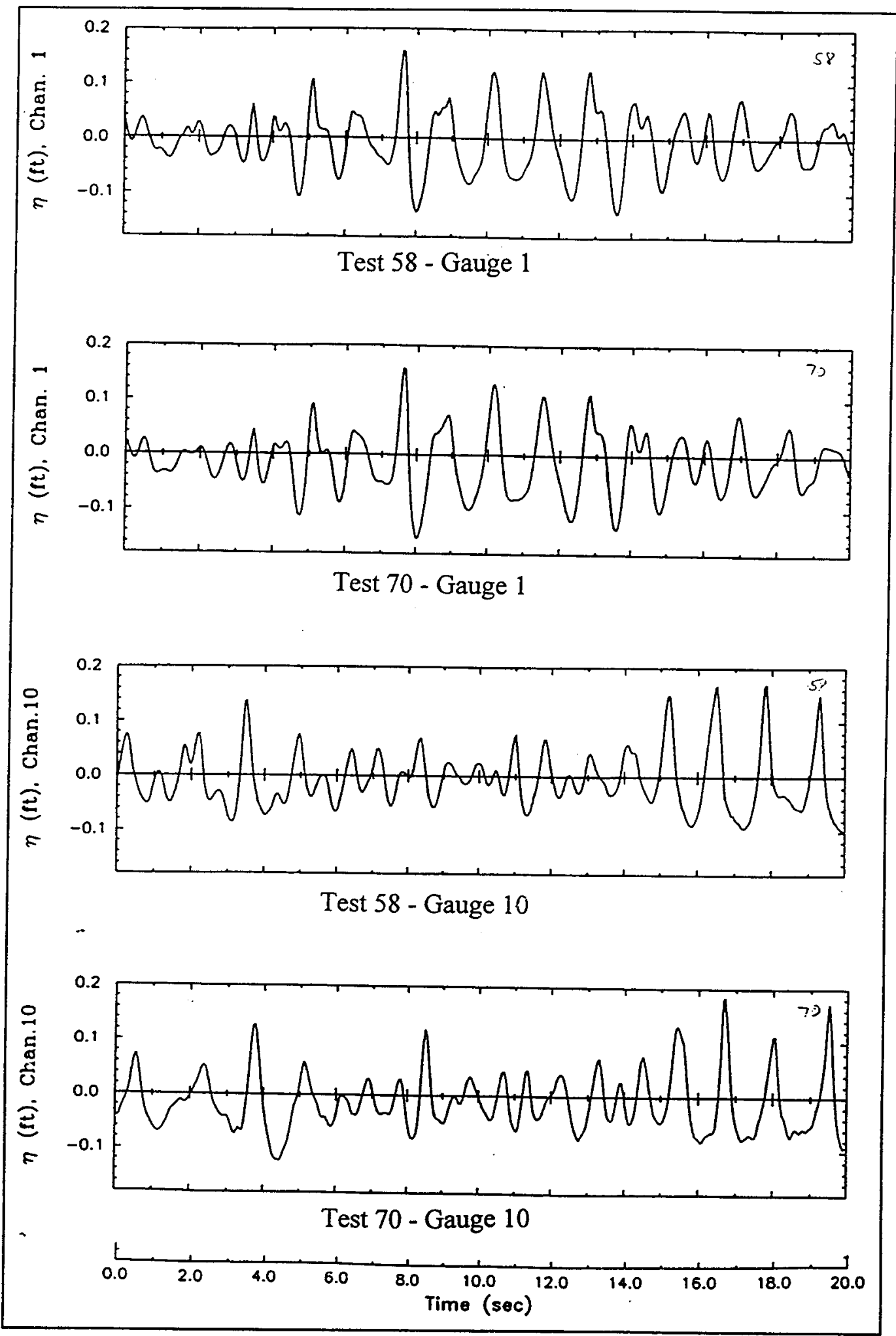

Figure 5. Snapshot of wave records at wave generator and in entrance channel at same time for a test without currents (Experiment 58) and with ebb currents (Experiment 70) 


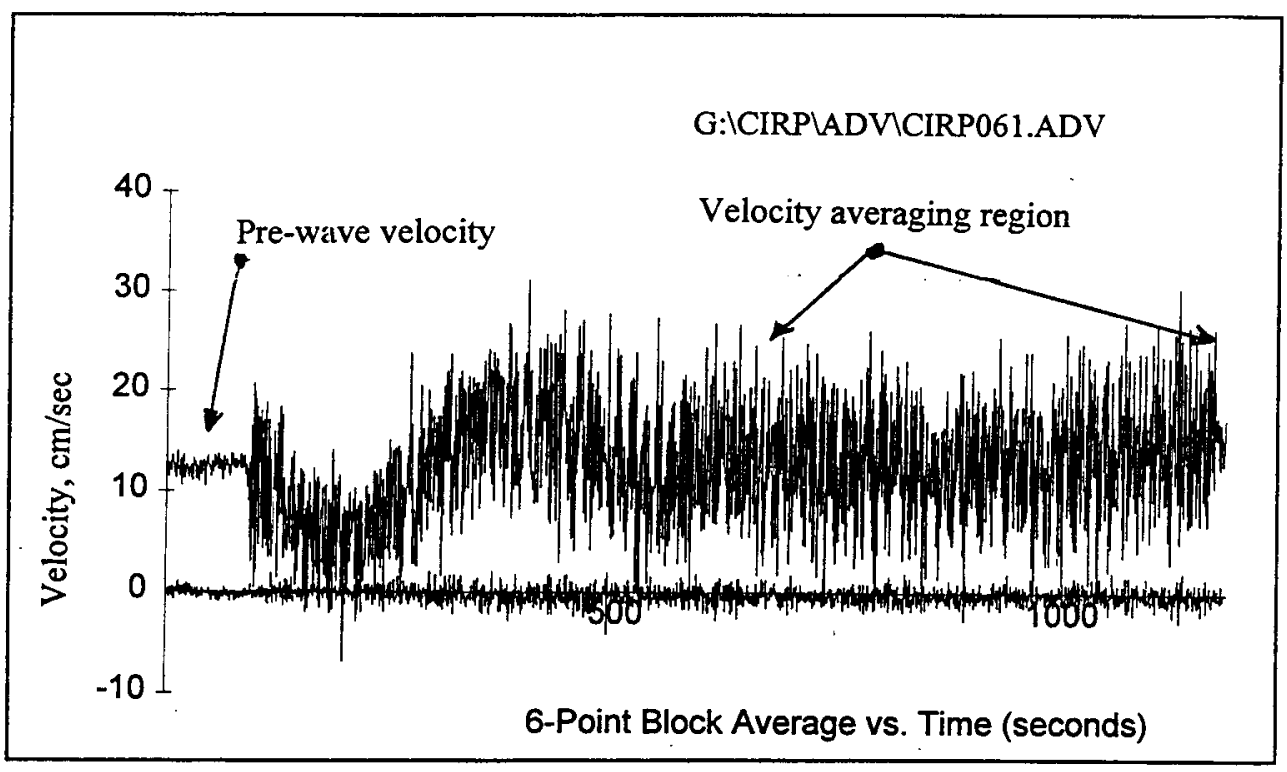

Figure 6. Time series of currents in channel at meter location 5 , run 61 
Wave data were analyzed in two ways. A down-crossing analysis was performed on the time series of water elevations as well as spectral analysis using a Fast Fourier Transform (FFT). For spectral analysis, the fundamental frequency, or $\Delta f$, was $0.00098 \mathrm{~Hz}(1 / 1020 \mathrm{~s})$. Forty frequency bands were averaged to produce the spectral density estimates. The downcrossing analysis produced the calculated parameters shown in Table 3.

\begin{tabular}{|c|c|}
\hline \multicolumn{2}{|c|}{$\begin{array}{l}\text { Table } 3 \\
\text { Calculated Wave Parameters from Downcrossing Analysis }\end{array}$} \\
\hline Parameter Name & Description \\
\hline ETABAR & Average water level \\
\hline ETAMIN & Minimum water surface elevation \\
\hline ETARMS & Root-mean-square water surface elevation \\
\hline ETAMAX & Maximum water surface elevation \\
\hline ETASD & Standard deviation of water surface elevation \\
\hline RHOHH & Correlation between wave heights \\
\hline RHOHT & Correlation between heights and periods \\
\hline HMIN & Smallest wave height \\
\hline HMAX & Largest wave height \\
\hline HBAR & Average wave height \\
\hline H 1/3 & $\begin{array}{l}\text { Significant wave height, average of highest } 33 \text { percent of wave } \\
\text { heights }\end{array}$ \\
\hline H $1 / 10$ & Average of highest 10 percent of wave heights \\
\hline H 1/20 & Average of highest 5 percent of wave heights \\
\hline H $1 / 100$ & Average of highest 1 percent of wave heights \\
\hline TBAR & Average wave period \\
\hline $\mathrm{T} 1 / 3$ & $\begin{array}{l}\text { Significant wave period, average period of highest } 33 \text { percent of } \\
\text { waves }\end{array}$ \\
\hline $\mathrm{T} 1 / 10$ & Average wave period of highest 10 percent of wave heights \\
\hline $\mathrm{T} 1 / 20$ & Average wave period of highest 5 percent of wave heights \\
\hline $\mathrm{T} 1 / 100$ & Average wave period of highest 1 percent of wave heights \\
\hline WEIBULL ALPHA & \multirow{2}{*}{$\begin{array}{l}\text { For Rayleigh distribution of wave heights, alpha }=2 \text { and } \\
\text { beta }=0.5 \text {. Truncation of higher wave heights due to break- } \\
\text { ing increases alpha. }\end{array}$} \\
\hline WEIBULL BETA & \\
\hline NO. OF WAVES & Number of waves in record \\
\hline $\begin{array}{l}H(P=0.5) \\
(P=\text { probability })\end{array}$ & Median wave height \\
\hline$T(P=0.5)$ & Median wave period \\
\hline
\end{tabular}

The FFT or single channel frequency domain analysis was performed over the entire 20,400 data points $(\Delta t=0.05 \mathrm{sec})$. In the analysis the mean was removed and a cosine square taper applied over 10 percent of the data at the beginning and end of the data record. The spectral parameters calculated are listed in Table 4. Zero-moment wave heights, peak frequencies, and mean velocities for 12 cases 


\begin{tabular}{|c|c|c|}
\hline \multicolumn{3}{|c|}{$\begin{array}{l}\text { Table } 4 \\
\text { Calculated Wave Parameters from Single Channel Frequency Domain Analysis }\end{array}$} \\
\hline Parameter Name & Description & \\
\hline FPC & Peak frequency, CERC method & \\
\hline FPS & Peak frequency, single band & \\
\hline FPD & Peak frequency, Delft method & \\
\hline TPC & Peak period, CERC method & \\
\hline TPS & Peak period, single band & \\
\hline TPD & Peak period, Delft method & \\
\hline HMO & Wave height, zero moment & \\
\hline QPG & Spectral width parameter (Goda) & \\
\hline EMO & Zeroth moment of the energy spectrum & \\
\hline EM1 & First moment of the energy spectrum & \\
\hline EM2 & Second moment of the energy spectrum & \\
\hline TO2 & Average period, calculated as (EMO/EM2) 0.5 & \\
\hline
\end{tabular}

are given in Appendix A. The waves were averaged across the left, center, and right positions at gauges 2 through 7 . 


\section{Results}

\section{1-D Wave-Current Interaction}

The dispersion relationship for waves and currents traveling in the same direction or directly opposing each other is (Jonsson 1990, and others):

$$
\omega-k U=\sqrt{g k \tanh k d}
$$

where $\omega$ is angular frequency, $k$ is wave number, $U$ is current velocity, $g$ is gravitational acceleration, and $d$ is water depth. The wave period $(T=2 \pi / \omega)$ is assumed to remain constant as the wave propagates from still water onto the current. For the situation where $U=0$, Equation 2 reverts to the standard dispersion equation. Wave blocking (stopping of waves by an opposing current) occurs for relatively strong ebb currents for which there is no solution for Equation $2(|U|>(g T) /(8 \pi)$ in deep water and $|U|>(g d)^{1 / 3}$ in shallow water). The strong current prevents the wave from propagating through the channel, and the wave energy is reflected or dissipated by breaking.

Using $k$ calculated from Equation 2, the wavelength is given by:

$$
L=\frac{2 \pi}{k}
$$

In shallow water, Equation 2 reduces to:

$$
k=\frac{\omega}{U+\sqrt{g d}}
$$

and Equation 3 becomes:

$$
L=(U+\sqrt{g d}) T
$$


The wave height is determined from the conservation of wave action (Jonsson 1990, and others):

$$
\frac{\partial}{\partial x}\left(\frac{E\left(C_{g_{r}}+U\right)}{\omega_{r}}\right)=0
$$

where $E$ is wave energy, $C_{g r}$ is relative group velocity of the waves, $x$ is wave propagation direction, and $\omega_{r}$ is relative angular frequency. Equation 6 assumes no dissipation due to breaking or bottom friction. The subscript $r$ represents variables measured relative to the current, i.e., variables in a coordinate system moving with the current. This one-dimensional formulation was developed under the assumption of no refraction or diffraction, which is a reasonable assumption for normally indicident waves in the idealized inlet. The wave energy is determined from linear wave theory as:

$$
E=\frac{1}{8} \rho g H^{2}
$$

where $H$ is wave height and $\rho$ is water density. The relative angular frequency is given by:

$$
\omega_{r}=\sqrt{g k \tanh k h}
$$

Equation 8 is similar to Equation 2 for the situation of $U=0$, but its application is different. Equation 8 is used to solve directly for $\omega_{r}$ with the value of $k$ determined from Equation 2. The relative group velocity is given by:

$$
C_{g_{r}}=\frac{1}{2} \frac{\omega_{r}}{k}\left(1+\frac{2 k h}{\sinh 2 k h}\right)
$$

Applying Equation 6 between an offshore Region 1 where the current is negligible and a Region 2 in the channel (which may have a different depth and a current) gives:

$$
\left(\frac{E C_{g}}{\omega}\right)_{1}=\left(\frac{E\left(C_{g_{r}}+U\right)}{\omega_{r}}\right)_{2}
$$

Solving for the wave height in Region 2 gives: 


$$
\begin{array}{r}
H_{2}=H_{1} \sqrt{\left(\frac{C_{g}}{\omega}\right)_{1}\left(\frac{\omega_{r}}{C_{g_{r}}+U}\right)_{2}}= \\
H_{1} \sqrt{\left(\frac{C_{g_{1}}}{C_{g_{r_{2}}}+U_{2}}\right)\left(\frac{1}{1+\frac{U_{2}}{C_{r_{2}}}}\right)}
\end{array}
$$

where $C=\omega r k$ is the wave celerity. The second expression on the right-hand side of Equation 11 for $H_{2}$ is obtained by substituting $\omega_{1}=\omega_{2}=\omega_{r 2}+k_{2} U_{2}$. If Regions 1 and 2 are both located in shallow water, Equation 11 reduces to:

$$
H_{2}=\frac{H_{1}}{\left(1+\frac{U_{2}}{\sqrt{g d}}\right)}
$$

\section{Breaking Formulations}

There is little information on breaking criteria for wave breaking on a current. Most nearshore breaking criteria neglect current and are based on relative water depth, defined as the ratio of wave height to water depth, but existing criteria that include wave steepness are good candidates for application on a current, e.g., Miche's criterion (1951) given by

$$
H_{\max }=0.142 L \tanh k d
$$

where $H_{\max }$ is the limiting regular wave height, $L$ is wavelength, $k$ is wave number, and $d$ is water depth. The strength of this relationship is that it reduces to a steepness limit in deep water and a depth limit in shallow water, thus incorporating both limiting factors in a simple form. Battjes and Janssen (1978) applied the Miche criterion with the concept of energy dissipation in a bore (LeMehaute 1962) for irregular waves in the following form

$$
D=-0.25 Q_{b} f_{m} \frac{H_{\max }^{3}}{d}
$$


where $D$ is the wave energy dissipation rate, $Q_{b}$ is the percentage of waves breaking (function of the ratio of root-mean-square wave height to $H_{m a x}$ ), and $f_{m}$ is the mean frequency.

Another class of breaking relationships with possible application to currents are the whitecapping formulations used in spectral wave generation models

(Hasselmann 1974). Two such relationships are:

$$
D=-a S^{4} \omega_{m} \frac{k}{k_{m}} E(\omega)
$$

given by Komen, Hasselmann, and Hasselmann (1984) and Komen et al. (1994), where $a$ is a coefficient, $S$ is an integrated relative steepness parameter, $\omega_{m}$ is the mean angular frequency, $k_{m}$ is the mean wave number, $E$ is the energy density spectrum, $\omega$ is angular frequency; and

$$
D=-\frac{\varepsilon g^{0.5} E(f)^{3} k_{m}^{4.5}}{\tanh \left(k_{m} d\right)^{0.75}}
$$

given by Resio (1987), where $\varepsilon$ is a coefficient and $f$ is wave frequency. These dissipation relationships were developed for waves in the absence of current, but they are applied in this study of breaking on a current to give insight about the processes.

\section{Spectra}

Selected spectra from two runs are shown in Figures 7 and 8 (additional spectra are given in Appendix B). The peak periods for the runs were 0.7 and $1.4 \mathrm{~s}$, respectively, the incident height for both cases was $5.5 \mathrm{~cm}$, and the current was $24 \mathrm{~cm} / \mathrm{s}$. The curves are labeled for gauges $0,1,3$, and 6 ; with gauge 0 offshore (near the wave generator, average of wave gauges 1-7 in Figure 3), gauge 1 approximately $3 \mathrm{~m}$ offshore of the jetty heads (wave gauge 8 in Figure 3), gauge 3 near the jetty heads (wave gauge 10 in Figure 3), and gauge 6 approximately $3 \mathrm{~m}$ inshore of the jetty heads. The spectra show interesting trends. First, Figure $7\left(T_{p}=0.7 \mathrm{~s}\right)$ shows a significant downshifting of the peak frequency from the offshore (gauge 0 ) toward the inlet throat (gauge 6). The peak period increased up to 16 percent for $U=24 \mathrm{~cm} / \mathrm{s}, 9$ percent for $U=14 \mathrm{~cm} / \mathrm{s}$, and varied by $0-6$ percent for no current. Lai, Long, and Huang (1989) reported a similar trend which they attribute to nonlinear side band instabilities. The energy dissipated through breaking was extracted at the peak frequency and higher, with the slope of the high-frequency tail of the spectra remaining fairly constant. This implies that dissipation is related to energy at a given frequency or energy is nonlinearly redistributed to maintain the high-frequency slope. The energy in the low-frequency end of the spectra increased, most noticeably in the cases with longer peak periods (e.g., Figure 8), with and without current. 


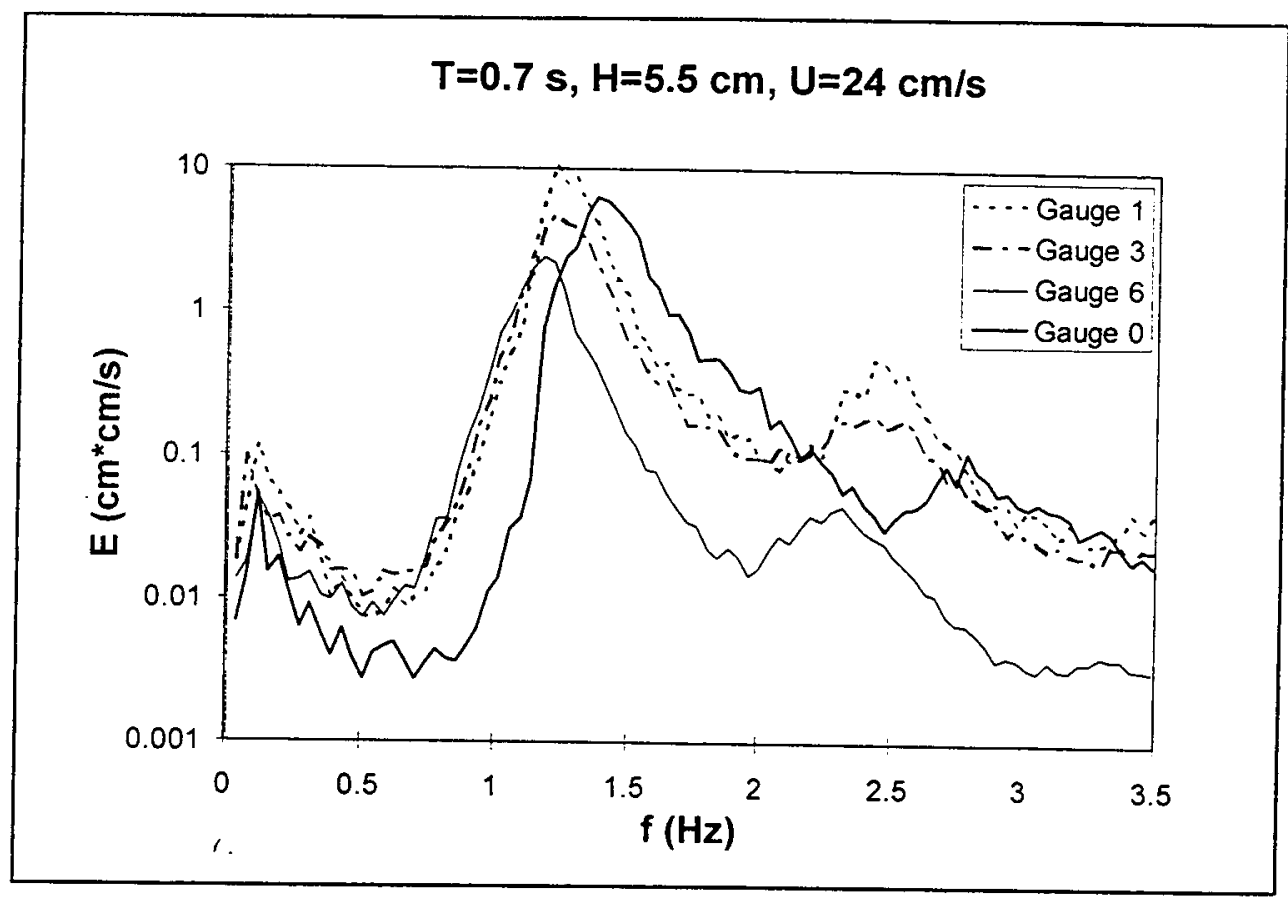

Figure 7. Spectra for $T_{p}=0.7 \mathrm{~s}, H_{m o}=5.5 \mathrm{~cm}$, and $U=24 \mathrm{~cm} / \mathrm{s}$

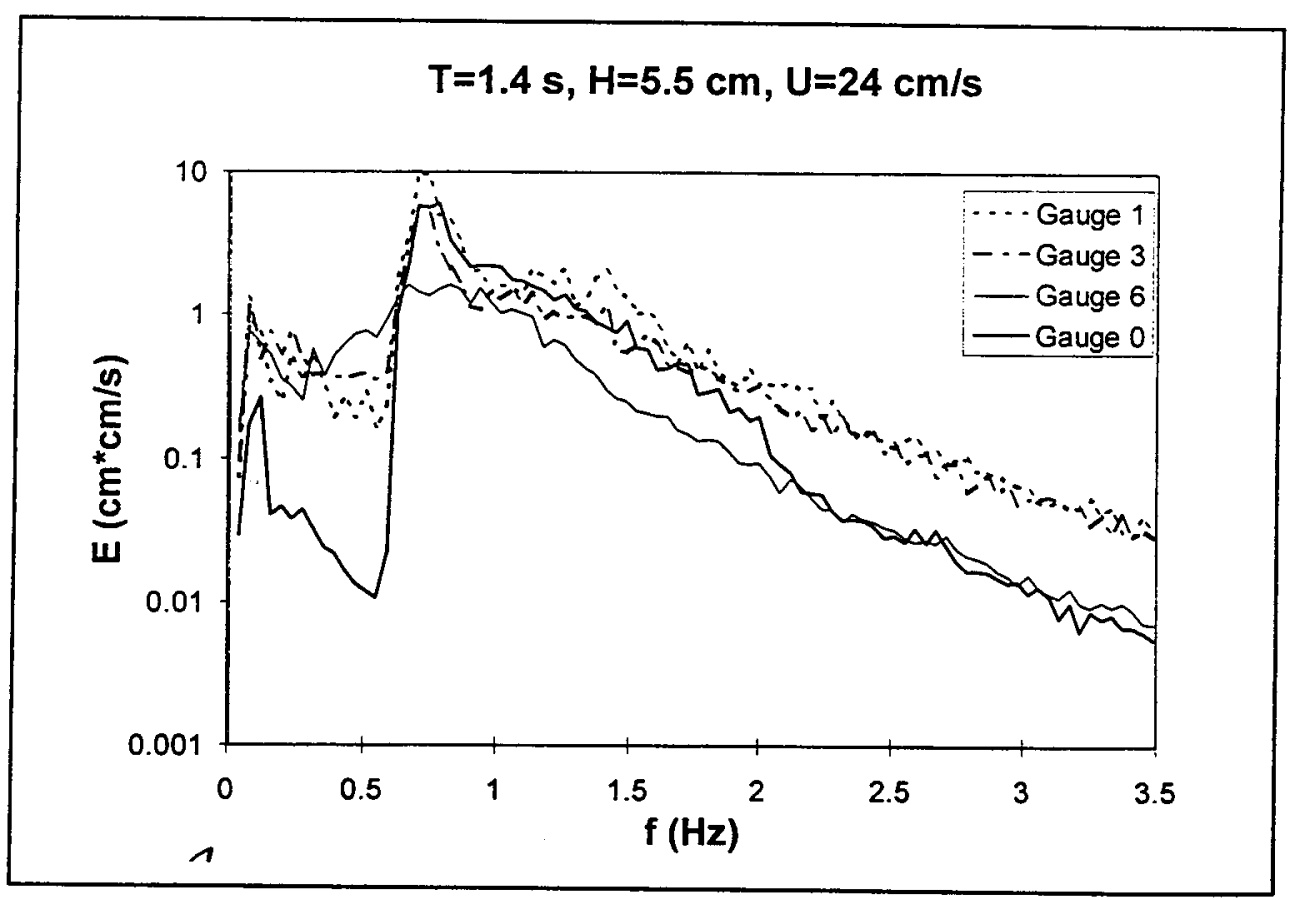

Figure 8. Spectra for $T_{\rho}=1.4 \mathrm{sec}, H_{m o}=5.5 \mathrm{~cm}$, and $U=24 \mathrm{~cm} / \mathrm{s}$ 


\section{Calculating Wave Breaking on a Current}

\section{Dissipation rates}

The motivation for these laboratory experiments was to find a wave dissipation formulation for wave breaking on a current that can be applied in numerical wave-transformation models. Two likely parameters to correlate with dissipation are wave steepness (as in deepwater breaking and whitecapping relationships) and wave height (as in bore dissipation models). Also, existing dissipation formulations discussed in the introduction are evaluated with dissipation calculated from the measurements.

Dissipation was calculated from the laboratory measurements by applying the action balance equation, Equation 6, modified to include energy dissipation:

$$
\frac{\partial}{\partial x}\left(E \frac{\left(C_{g r}+U\right)}{\omega_{r}}\right)=\frac{D}{\omega_{r}}
$$

The action balance equation was applied between two wave gauges to solve for the dissipation $D$. Figures 9 and 10 show the calculated dissipation as a function of steepness and wave height, respectively. Figure 9 shows that the steepness parameterization segregates the data by peak wave period. Although dissipation increases with steepness, for a given steepness, dissipation is higher for longer peak periods. This result foreshadows that the whitecapping dissipation formulations, which are strongly a function of wave steepness, will not provide good estimates of dissipation for this data set. The calculated dissipation is highly correlated with wave height, and wave period does not seem to be a controlling parameter (Figure 10). This wave-height dependence implies that bore-type dissipation formulations, which are functions of wave height, are good candidates for estimating dissipation for this data set. Figure 11 shows the Miche limit (Equation 13) in terms of maximum wave steepness as a function of relative depth (solid line). The measurements, some of which correspond to breaking and some do not, also are plotted. The Miche criterion serves as a conservative upper limit to the data. The conservatism is not surprising because the formulation is for regular waves, and the data correspond to irregular waves.

Three dissipation formulations were evaluated with the laboratory data, those of Komen et al. (Equation 15), Resio (Equation 16), and Battjes and Janssen (Equation 14). Although current does not enter explicitly in any of these formulations, current has been included in the calculation of wavelength and wave number using conservation of waves and linear theory (see, e.g., Jonsson (1990)). The Resio formulation is given in Figure 12 as the solid line. This formulation slightly overpredicts 


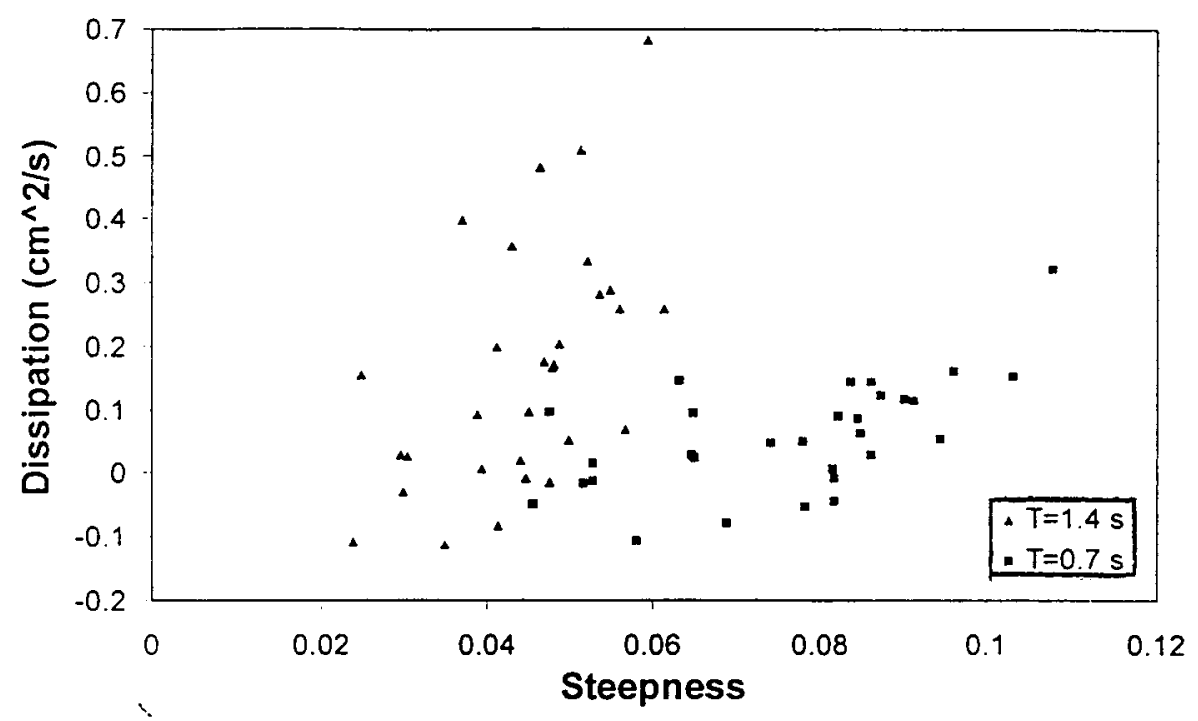

Figure 9. Dissipation versus steepness

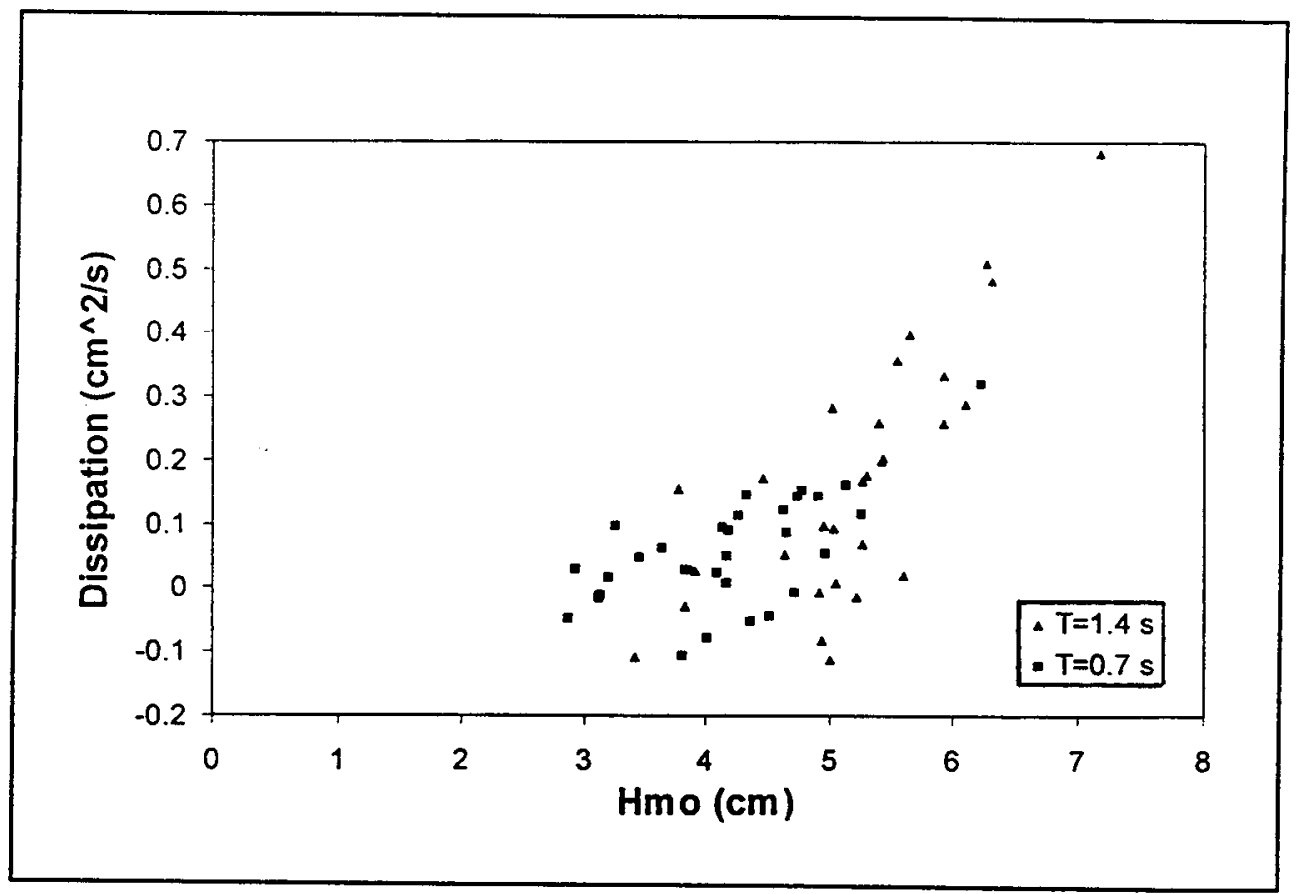

Figure 10. Dissipation versus wave height 


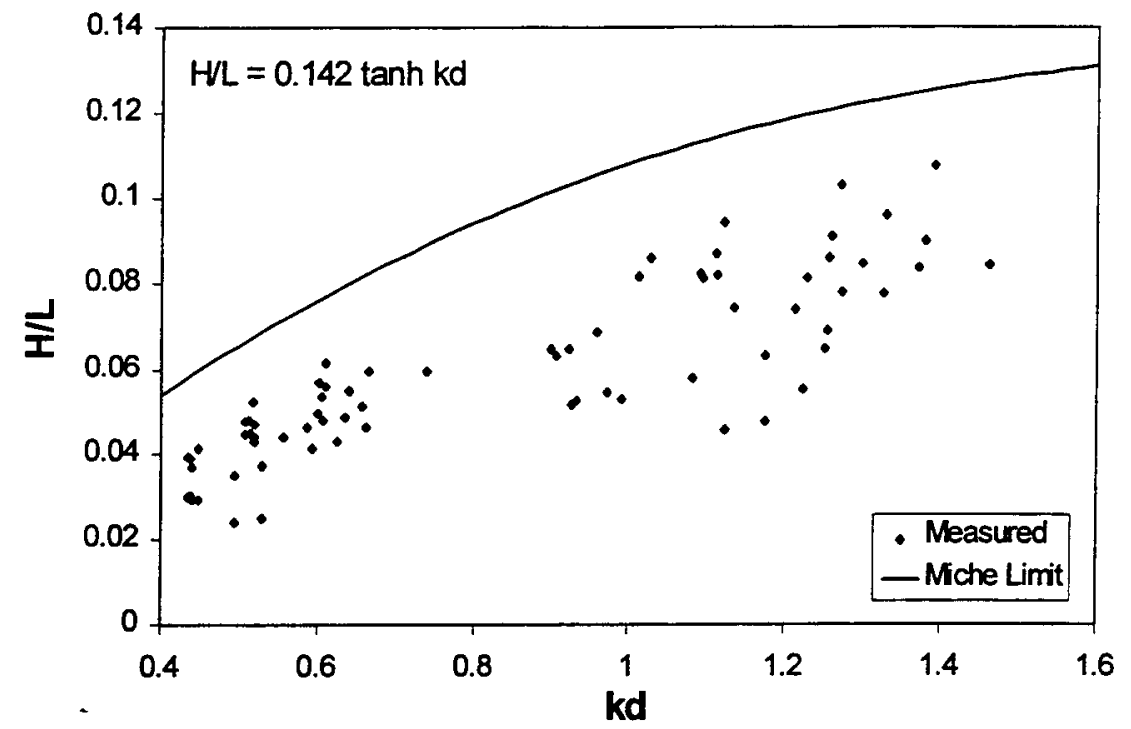

Figure 11. Miche criterion

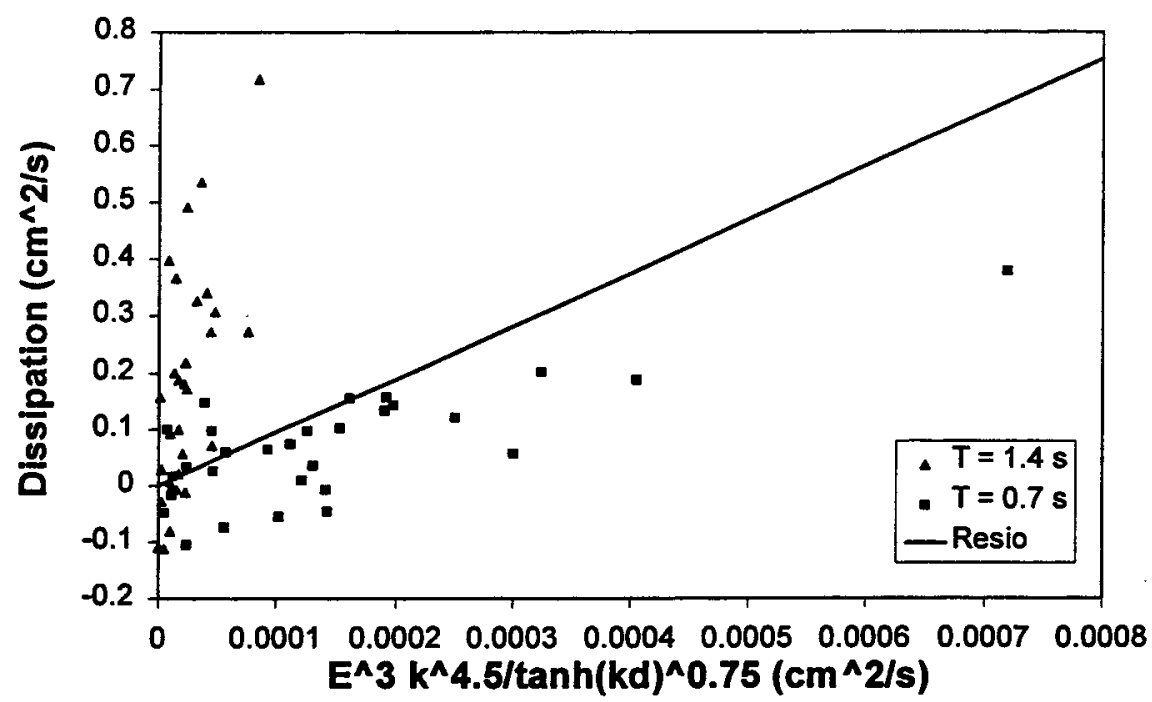

Figure 12. Resio dissipation 
dissipation for the 0.7-s waves, but significantly underpredicts dissipation for the 1.4-s waves. The correlation coefficient $\left(r^{2}\right)$ for the Resio formulation (both periods) is 0.46 . Likewise, the Komen et al. formulation (not shown) significantly underpredicts the dissipation for all wave conditions $\left(r^{2}=0\right)$. Because these two formulations are strongly dependent on wave steepness, it is expected that they correlate poorly with the data set (see Figure 9). It is not surprising that these white-capping expressions do not represent wave breaking on a current in shallow water, because the formulations were developed to balance excess wind input in saturated spectra without a current. The formulation of Battjes and Janssen is plotted in Figure 13 with the laboratory measurements and gives the correct trend in the data, but produces wide scatter (large deviation from the formulation), with a correlation coefficient of 0.25 .

The poor performance of the dissipation formulations led to development of an alternative relationship. Figure 10 showed good correlation of dissipation to wave height, so a form consistent with dissipation in a bore was assumed, and the following relationship was developed using linear regression:

$$
D=-0.002\left(\frac{g}{d}\right)^{\frac{1}{2}}\left(H_{m o}^{2}-H_{c}^{2}\right) \text { for } H_{m o}>H_{c}
$$

where $H_{c}$ is a critical wave height below which no dissipation occurs,

$$
H_{c}=0.08 L \tanh (k d)
$$

The wavelength and wave number in Equation 19 include modification by a current. Equation 18 was chosen to be of the form of Miche's criterion. Equation 18 is plotted against the laboratory data in Figure 14 and shows reasonable agreement $\left(r^{2}=0.78\right)$.

\section{Wave heights}

Applying the action balance equation (Equation 17) between the wave gauges, together with the various dissipation models, gives a simple one-dimensional shoaling and decay model. The Miche criterion also was applied as a dissipation function by limiting the wave energy based on the maximum wave height given by Equation 13. This transformation technique was used to calculate wave shoaling and breaking through the gauge array for each of the 12 runs. Cases without current had little or no wave height decay through the gauge array. Example cases with the greatest dissipation are presented in Figures 15-17 (additional cases are given in Appendix B). Note in the figures that the second point $(x=120 \mathrm{~cm})$ is consistently lower than the nearest points, probably due to a gauge calibration problem. This gauge also accounts for some of the scatter in the dissipation calculations. 


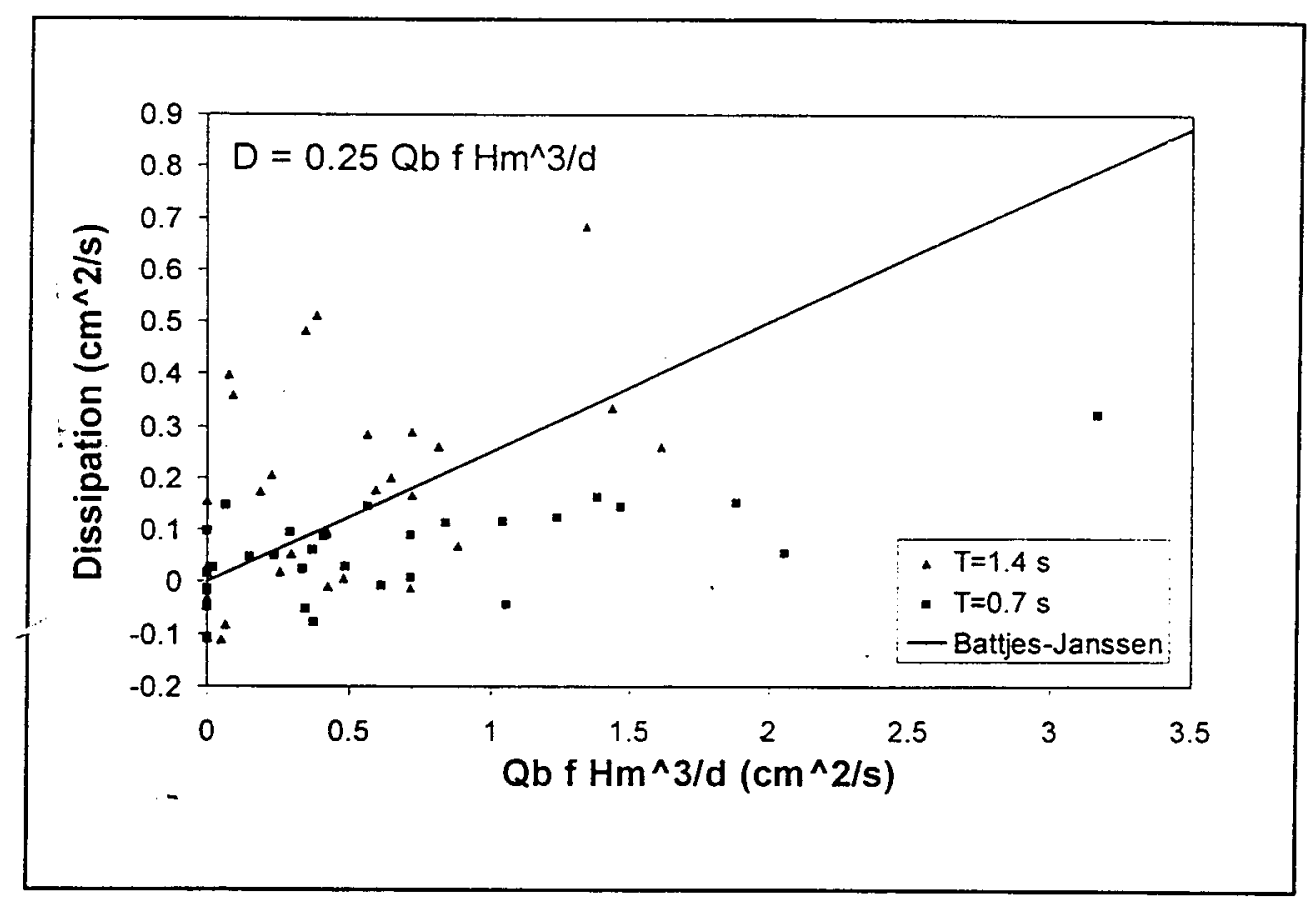

Figure 13. Battjes-Janssen dissipation

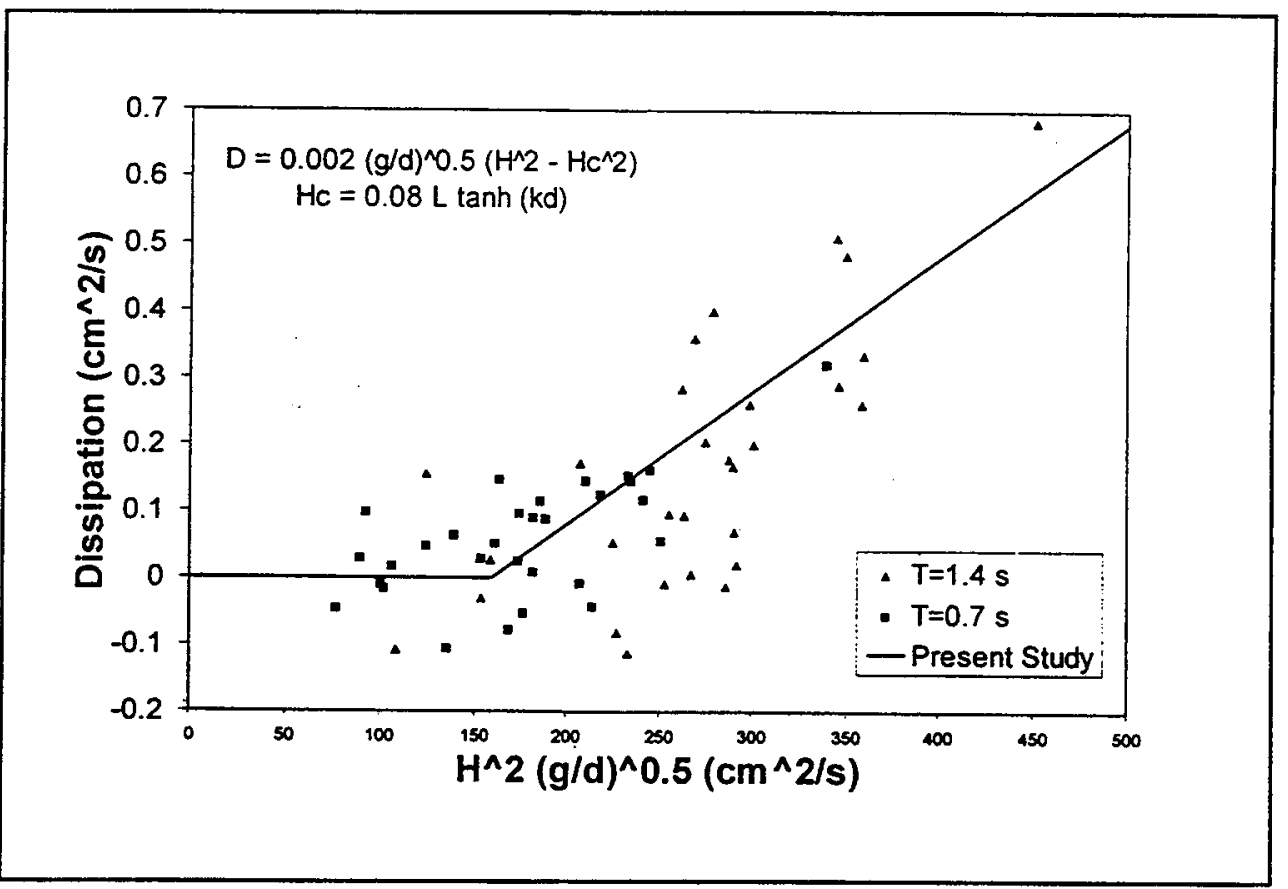

Figure 14. Present study dissipation 
The results generally cluster into two categories. The first category includes the formulations of Komen, Hasselmann, and Hasselmann; Miche; and Resio (for $T_{p}=$ $1.4 \mathrm{~s}$ ), which show little or no dissipation for almost all runs and thus significantly overpredict the wave height through the gauge array. In Figures 15 and 17, the Komen, Hasselmann, and Hasselmann and Miche curves generally overlay each other and predict no dissipation. Even in the cases with the highest wave height and strongest current (Figures 16 and 18), the Komen et al. formulation predicts little or no dissipation, whereas the Miche criterion predicts some wave height decay.

The second category includes the formulations of Battjes-Janssen, the present study (Equations 18 and 19), and Resio (for $T_{p}=0.7 \mathrm{~s}$ ). These formulations fall on the lower portions of the figures and agree well with the measured wave heights for the twelve cases, with the exception of cases with $T_{p}=0.7 \mathrm{~s}$ and $U=14 \mathrm{~cm} / \mathrm{s}$ (Figure 17). The reason for the poor agreement with this case is unclear. The correlation coefficient for the Resio formulation (both peak periods) was 0.71 , for the Battjes and Janssen formulation 0.86, and for the present study formulation 0.87. Therefore, in spite of the large scatter between the Battjes-Janssen dissipation relationship and the data, the prediction of wave height is generally good, essentially equivalent to the expression developed in this study.

\section{$T=1.4 \mathrm{~s}, H=5.5 \mathrm{~cm}, U=14 \mathrm{~cm} / \mathrm{s}$}

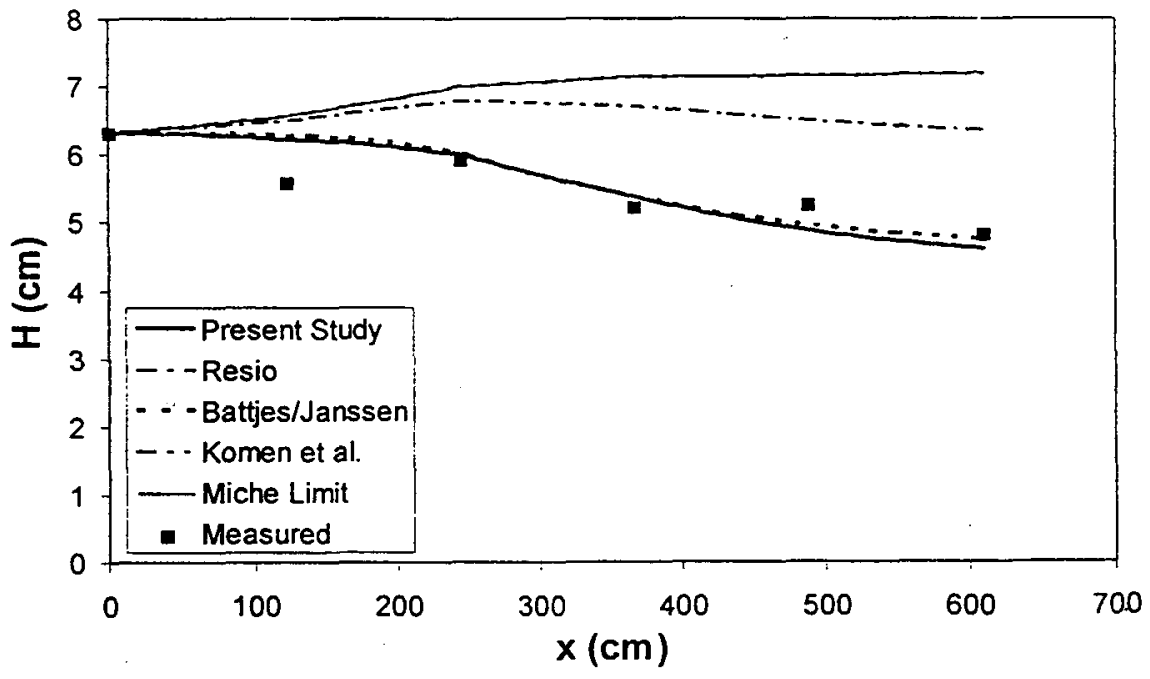

Figure 15. Wave height transformation for $T_{p}=1.4 \mathrm{~s}, H_{m o}=5.5 \mathrm{~cm}$, and $U=14 \mathrm{~cm} / \mathrm{s}$ 


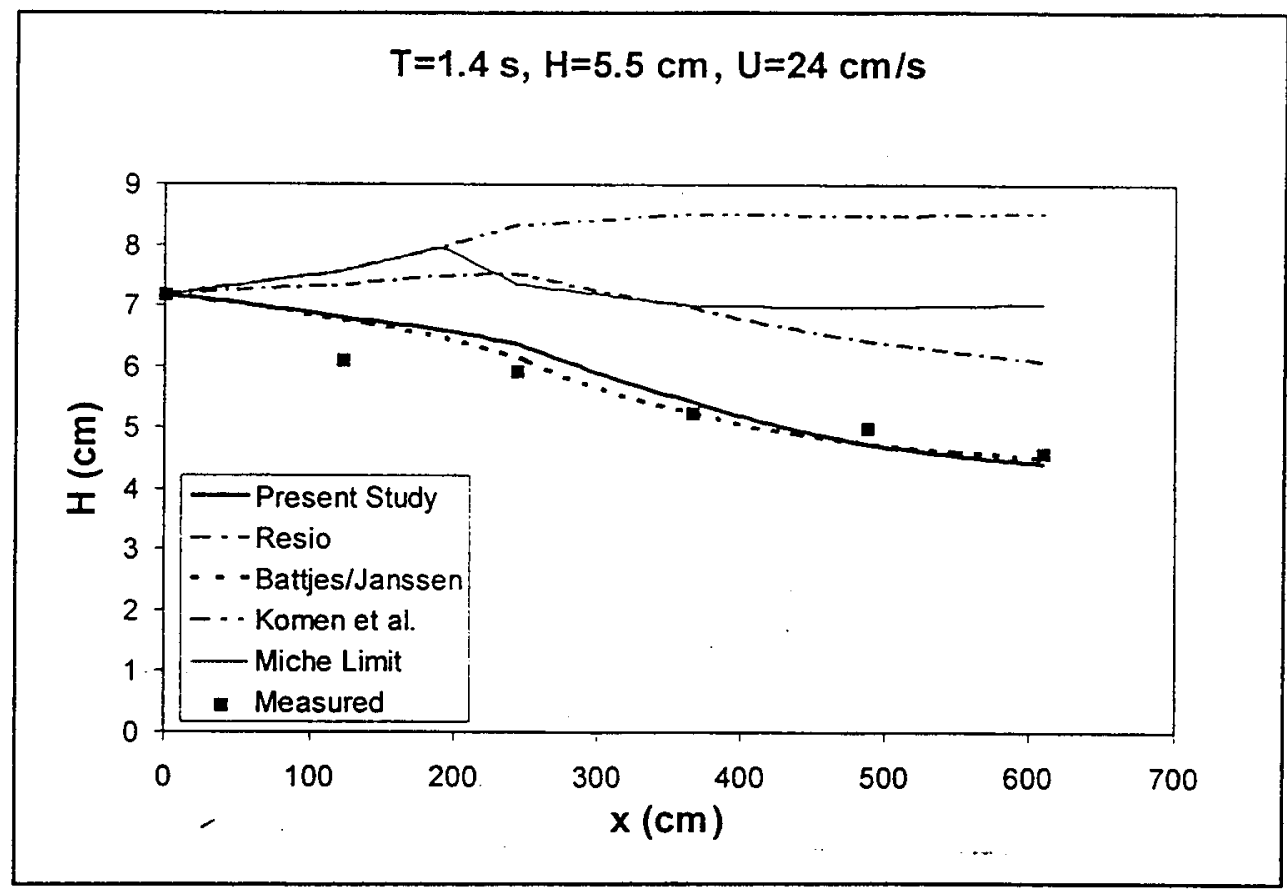

Figure 16. Wave height transformation for $T_{p}=1.4 \mathrm{~s}, H_{m o}=5.5 \mathrm{~cm}$, and $U=24 \mathrm{~cm} / \mathrm{s}$

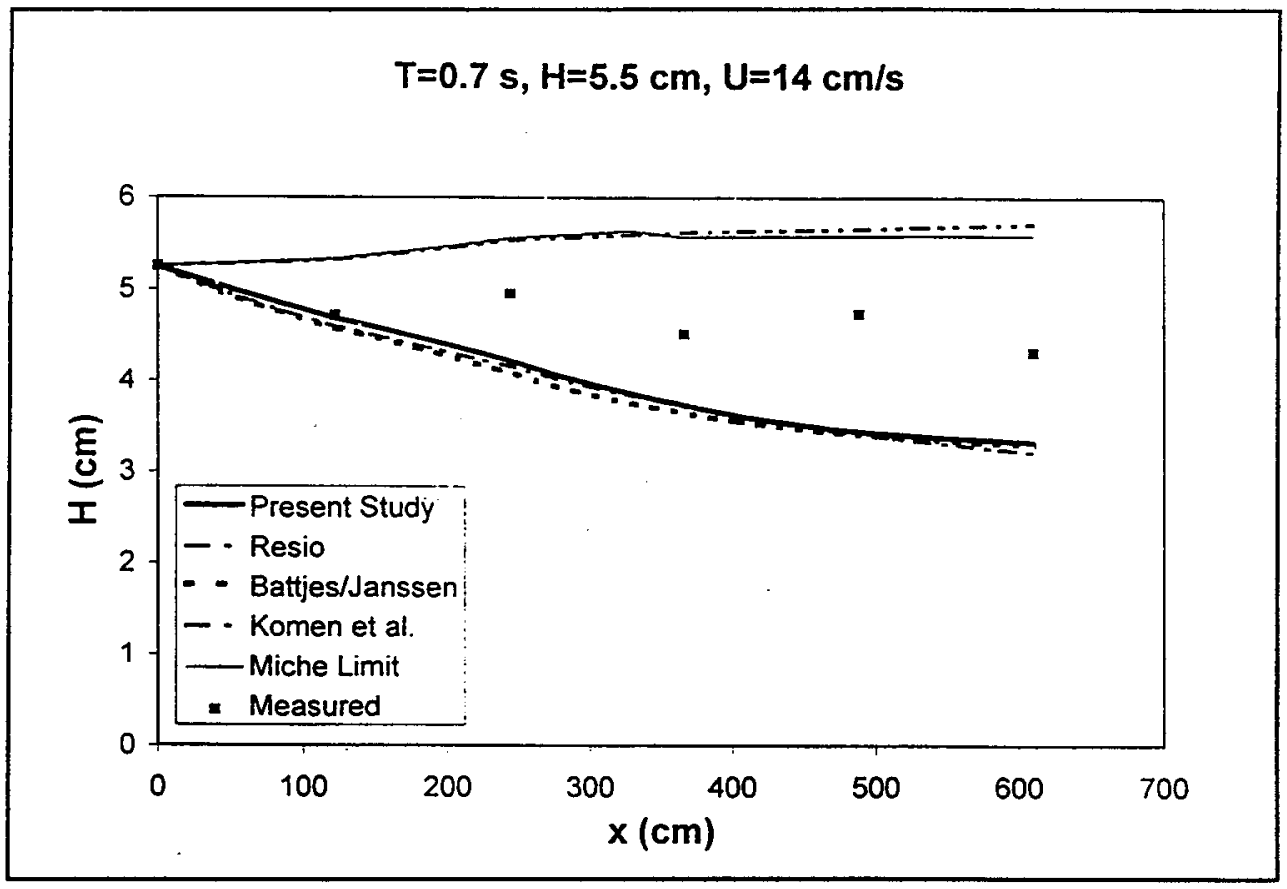

Figure 17. Wave height transformation for $T_{p}=0.7 \mathrm{~s}, H_{m o}=5.5 \mathrm{~cm}$, and $U=14 \mathrm{~cm} / \mathrm{s}$ 


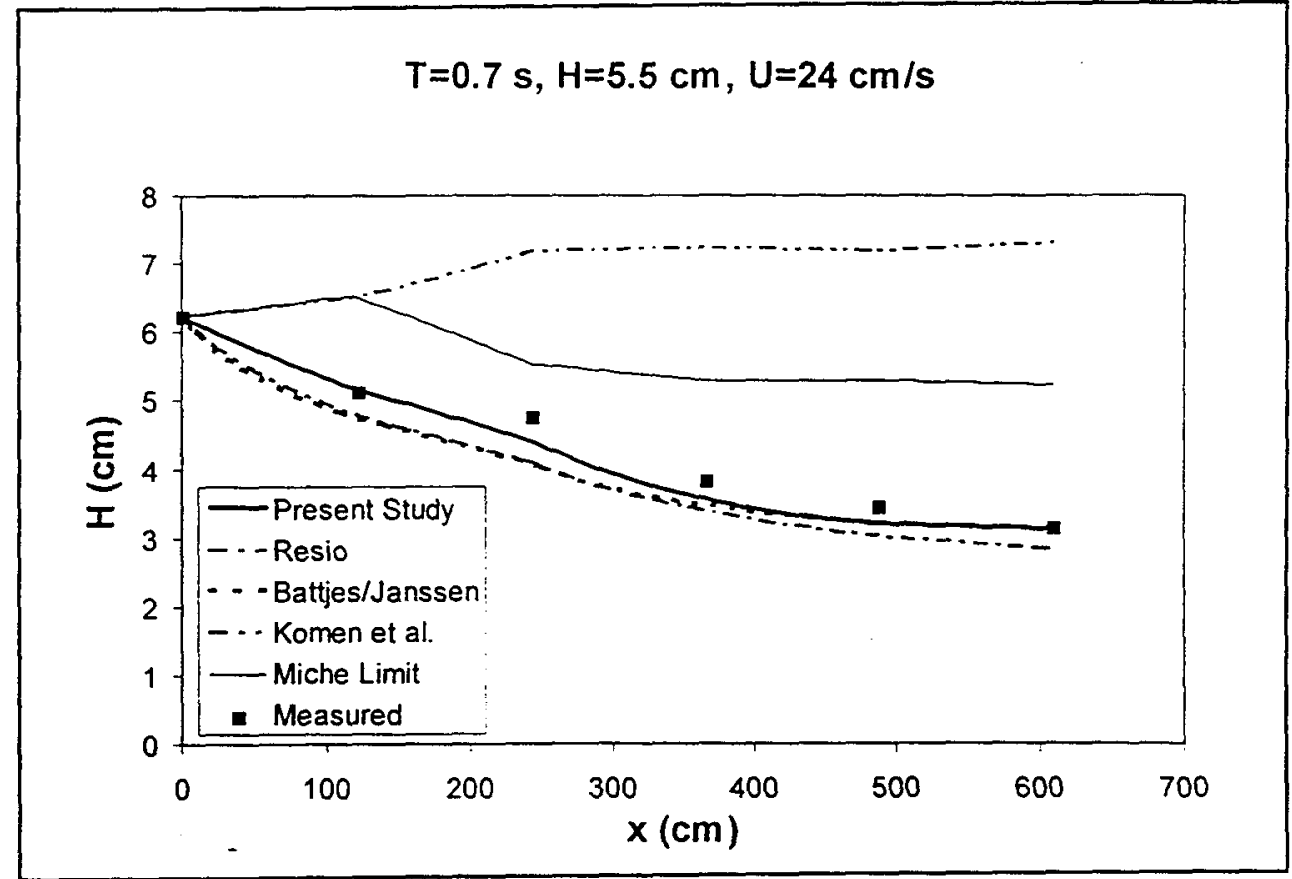

Figure 18. Wave height transformation for $T_{p}=0.7 \mathrm{~s}, H_{m o}=5.5 \mathrm{~cm}$, and $\mathrm{U}=24 \mathrm{~cm} / \mathrm{s}$ 


\section{Conclusions}

Results from a laboratory study of wave breaking on an ebb current at an idealized inlet are presented. The measurements show increased wave shoaling and breaking in the presence of the ebb current, as is expected from the conservation of waves and linear wave theory. The measurements also show a downshifting of the peak frequency (peak period became longer as much as 16 percent). Energy was dissipated at the peak and higher frequencies of the spectra. Dissipation rates calculated from the measurements were proportional to wave height.

Dissipation algorithms were examined with the data. Whitecapping formulations (Komen, Hasselmann, and Hasselmann 1984; Komen et al. 1994; Resio 1987), which are strongly dependent on wave steepness, generally underpredicted dissipation. Application of Resio's whitecapping formulation gave a correlation coefficient of 0.46 for predicting dissipation through the idealized inlet. The Battjes and Janssen breaking algorithm worked well for predicting wave height through the idealized inlet, despite considerable scatter in the dissipation prediction $\left(r^{2}=0.25\right)$. A relationship for dissipation as a function of wave height squared gave improved agreement between calculated and predicted dissipations $\left(r^{2}=0.78\right)$, but no substantial improvement over the Battjes and Janssen formulation for modeling the wave height.

A dissipation function or breaking criterion applied at a coastal inlet must include relative depth and wave steepness, as well as wave-current interaction. Depth-limited breaking is more important for longer period waves and steepness for shorter period waves.

The next phase of experiments in the idealized inlet includes construction of an ebb shoal and extension of the measurement array farther offshore. Breaking over the ebb shoal, wave blocking, scaling relationships, and oblique wave incidence will be studied. 


\section{References}

Battjes, J. A., and Janssen, J. P. F. M. (1978). "Energy loss and set-up due to breaking of random waves," Proc. 16th Coast. Engrg. Conf., ASCE, New York, 569-587.

Dean, R. G. (1977). "Equilibrium beach profiles: U.S. Atlantic and Gulf Coasts," Ocean Engineering Technical Report No. 12, Dept of Civil Engineering and College of Marine Studies, University of Delaware, Newark.

Hasselmann, K. (1974). "On the spectral dissipation of ocean waves due to whitecapping," Boundary-Layer Meteorology 6(1-2), 107-127.

Hedges, T. S., Anastasiou, K., and Gabriel, D. (1985). "Interaction of random waves and currents," J. Wtrway., Port, Coast., and Oc. Engrg. 111(2), 275288.

Jonsson, I. G. (1990). "Wave-current interactions." The Sea.

B. LeMehaute and D. M. Hanes, ed., John Wiley \& Sons, Inc., New York, 65-120.

Komen, G. J., Hasselmann, S., and Hasselmann, K. (1984). "On the existence of a fully developed wind-sea spectrum," J. Phys. Oceanogr. 14, 1271-1285.

Komen, G. J., Cavaleri, L., Donelan, M., Hasselmann, K., Hasselmann, S., and Janssen, P. A. E. M. (1994). Dynamics and modelling of ocean waves. Cambridge, $300 \mathrm{pp}$.

Lai, R. J., Long, S. R., and Huang, N. E. (1989). "Laboratory studies of wave-current interaction: kinematics of the strong interaction," J. Geophys. Res. , 97(C11), 16,201-16,214.

LeMehaute, B. (1962). "On non-saturated breakers and the wave run-up." Proc. 8th Coast. Engrg. Conf. ASCE, New York, 77-92. 
Miche, M. (1951). "Le pouvoir reflechissant des ouvrages maritimes exposes a l' action de la houle." Annals des Ponts et Chaussess. 121e Annee, 285-319 (translated by Lincoln and Chevron, University of California,

Berkeley, Wave Research Laboratory, Series 3, Issue 363, June 1954).

Resio, D. T. (1987). "Shallow-water waves; I: Theory," J. Wtrway., Port, Coast., and Oc. Engrg. 113(3), 264-281.

Ris, R. C., and Holthuijsen, L. H. (1996). "Spectral modelling of current induced wave-blocking." Proc. 25th Coast. Engrg. Conf. ASCE, New York, $1247-1254$

Stevens, J. C. (1942). "Hydraulic models," Manuals of Engineering Practice No. 25, American Society of Civil Engineers, New York.

Suh, K. D., Kim, Y.-Y., and Lee, D. Y. (1994). "Equilibrium-range spectrum of waves propagating on currents," J. Wtrway., Port, Coast., and Oc. Engrg. $120(5), 434-450$. 


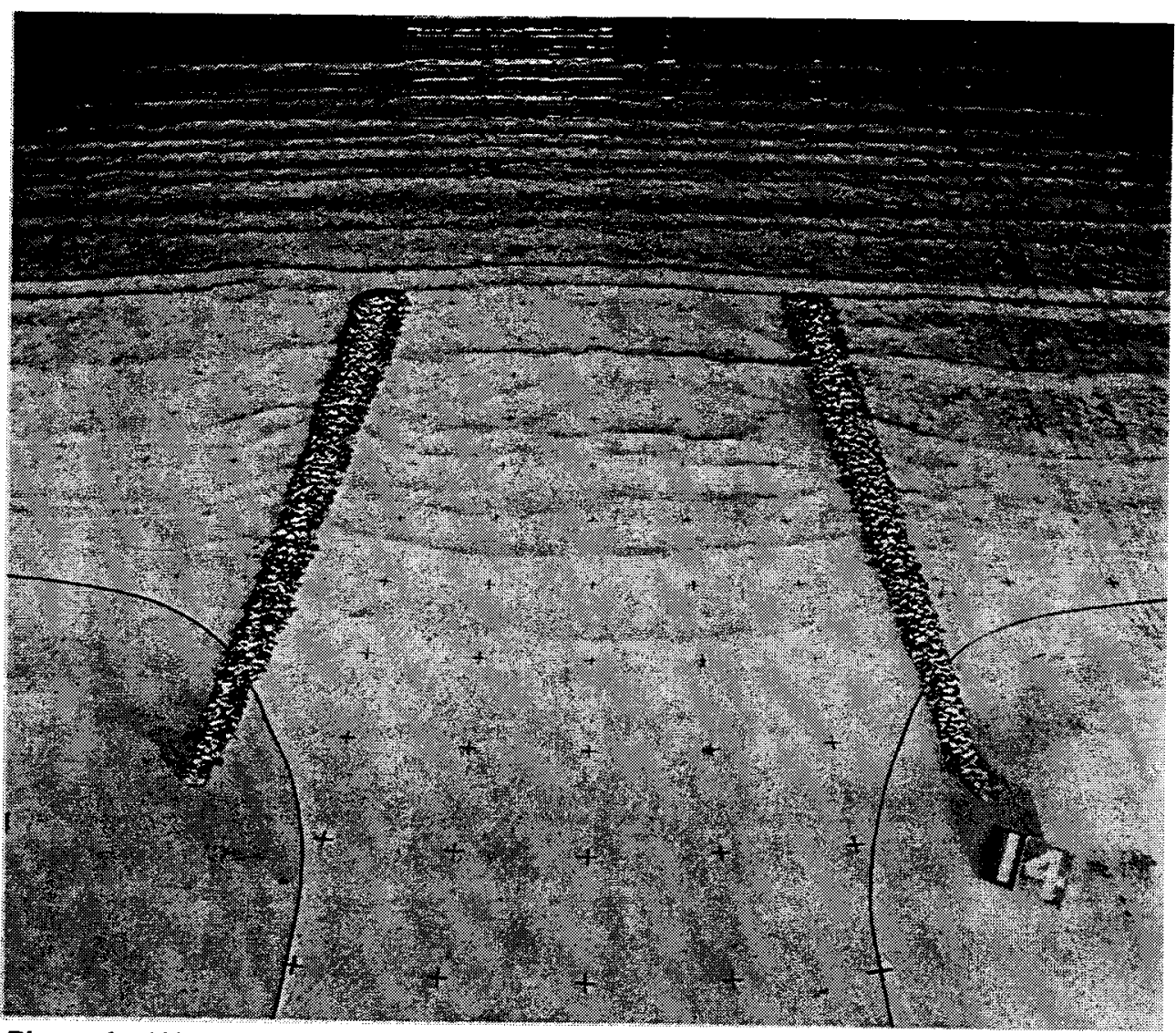

Photo 1. Wave height: $5.5 \mathrm{~cm}$, wave period: $1.4 \mathrm{sec}$, no current 


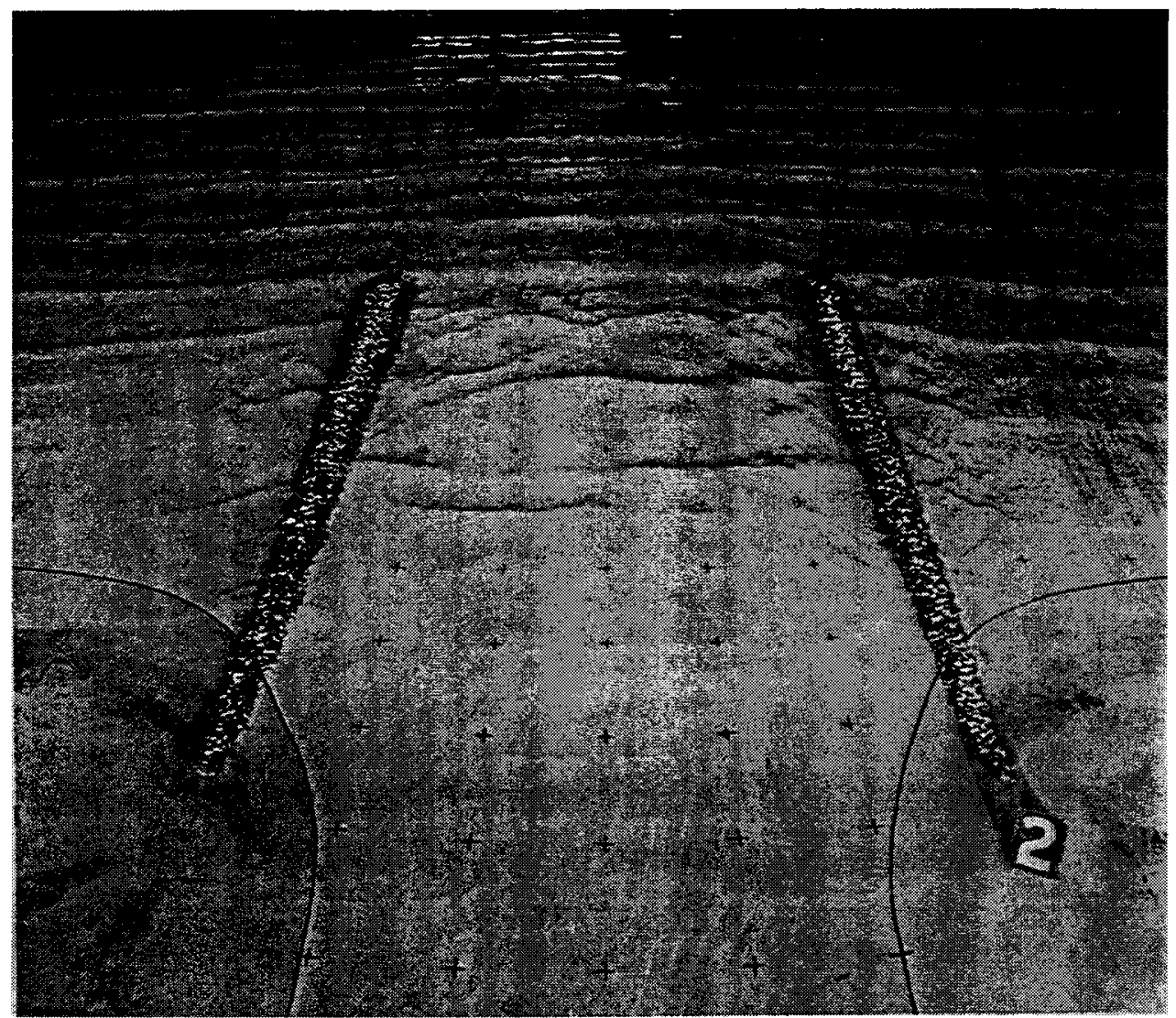

Photo 2. Wave height: $5.5 \mathrm{~cm}$, wave period: $1.4 \mathrm{sec}$, ebb current: $12 \mathrm{~cm} / \mathrm{sec}$ 


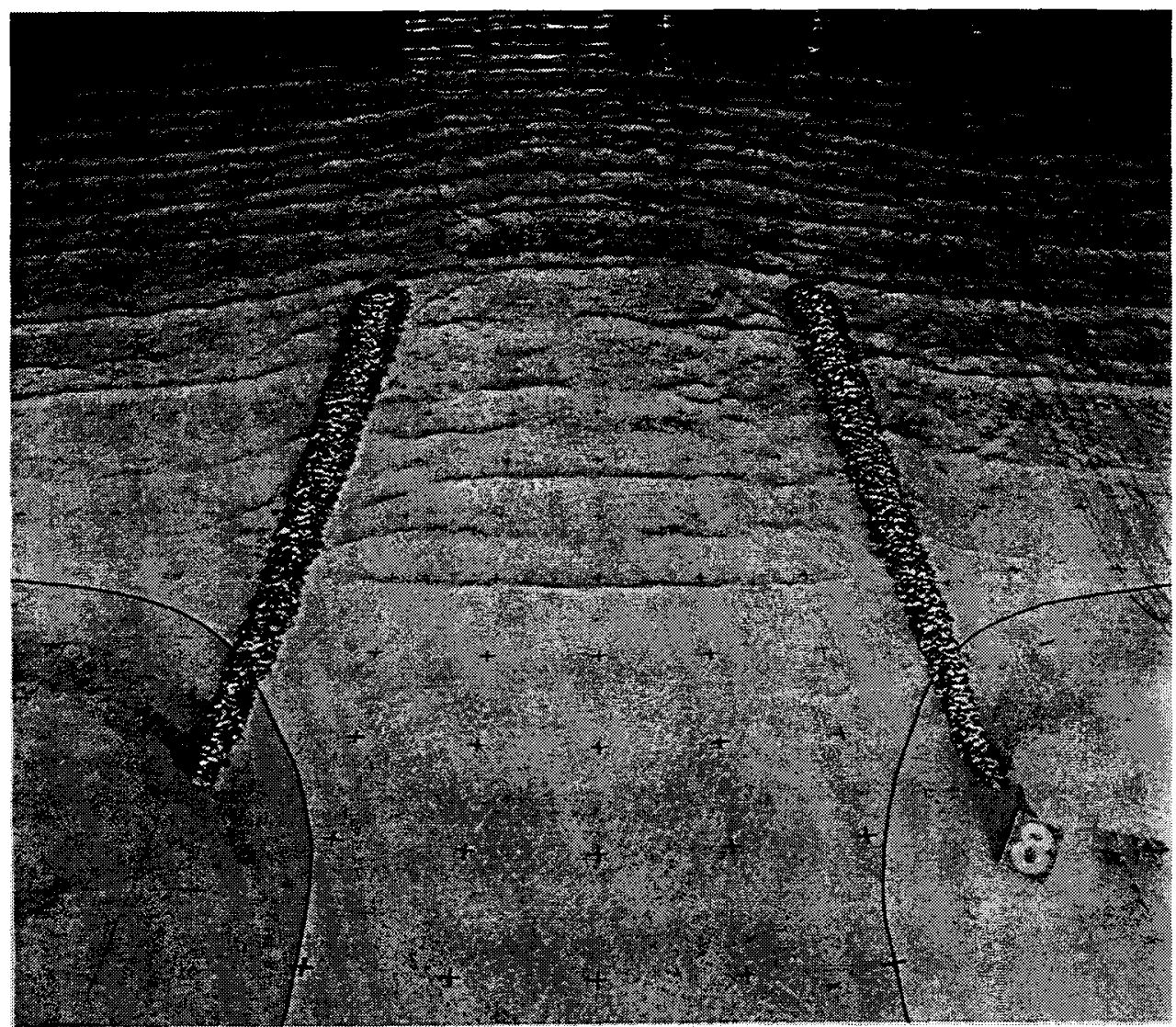

Photo 3. Wave height: $5.5 \mathrm{~cm}$, wave period $1.4 \mathrm{sec}$, ebb current: $24 \mathrm{~cm} / \mathrm{sec}$ 


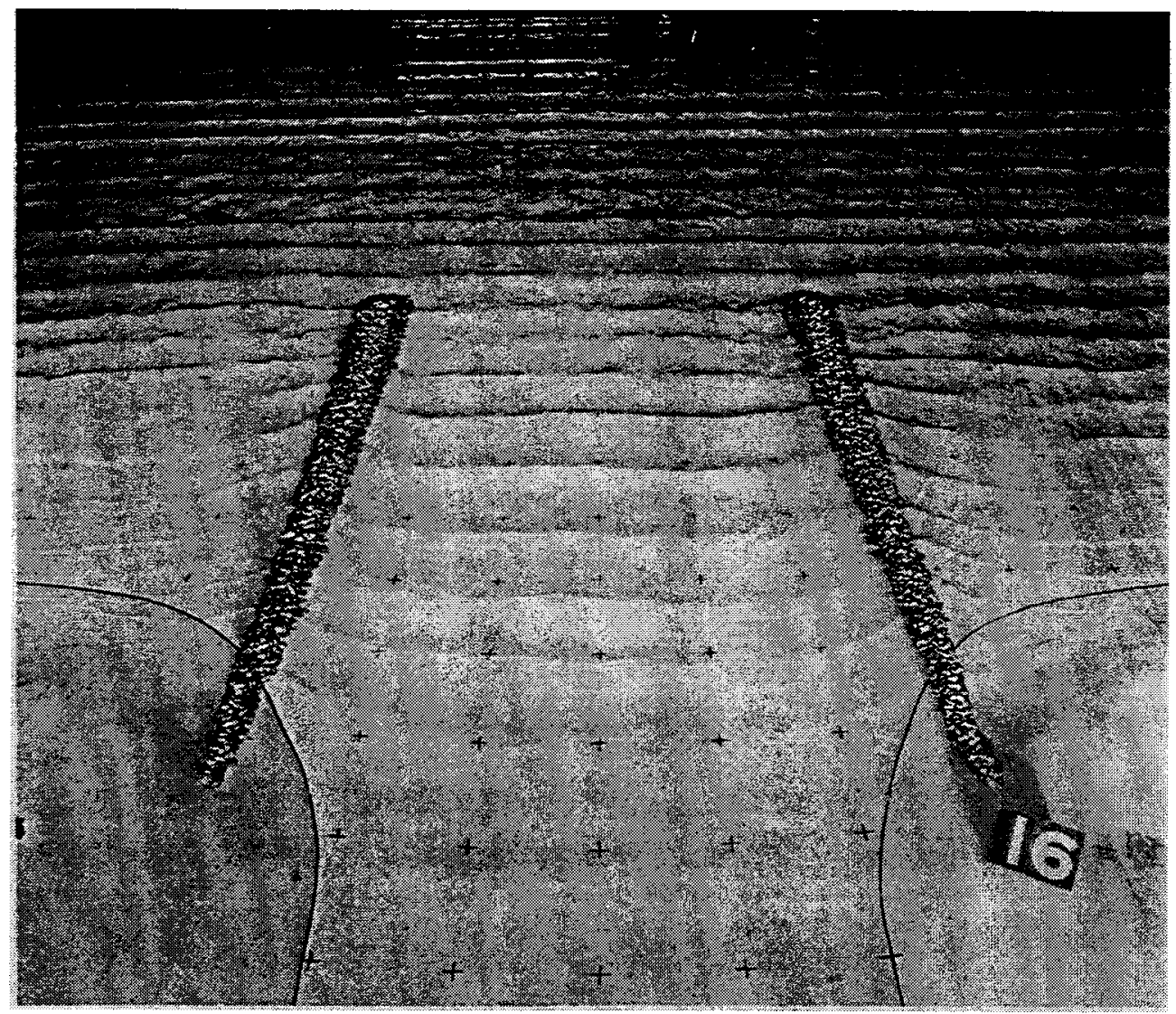

Photo 4. Wave height: $5.5 \mathrm{~cm}$, wave period $0.7 \mathrm{sec}$, no current 


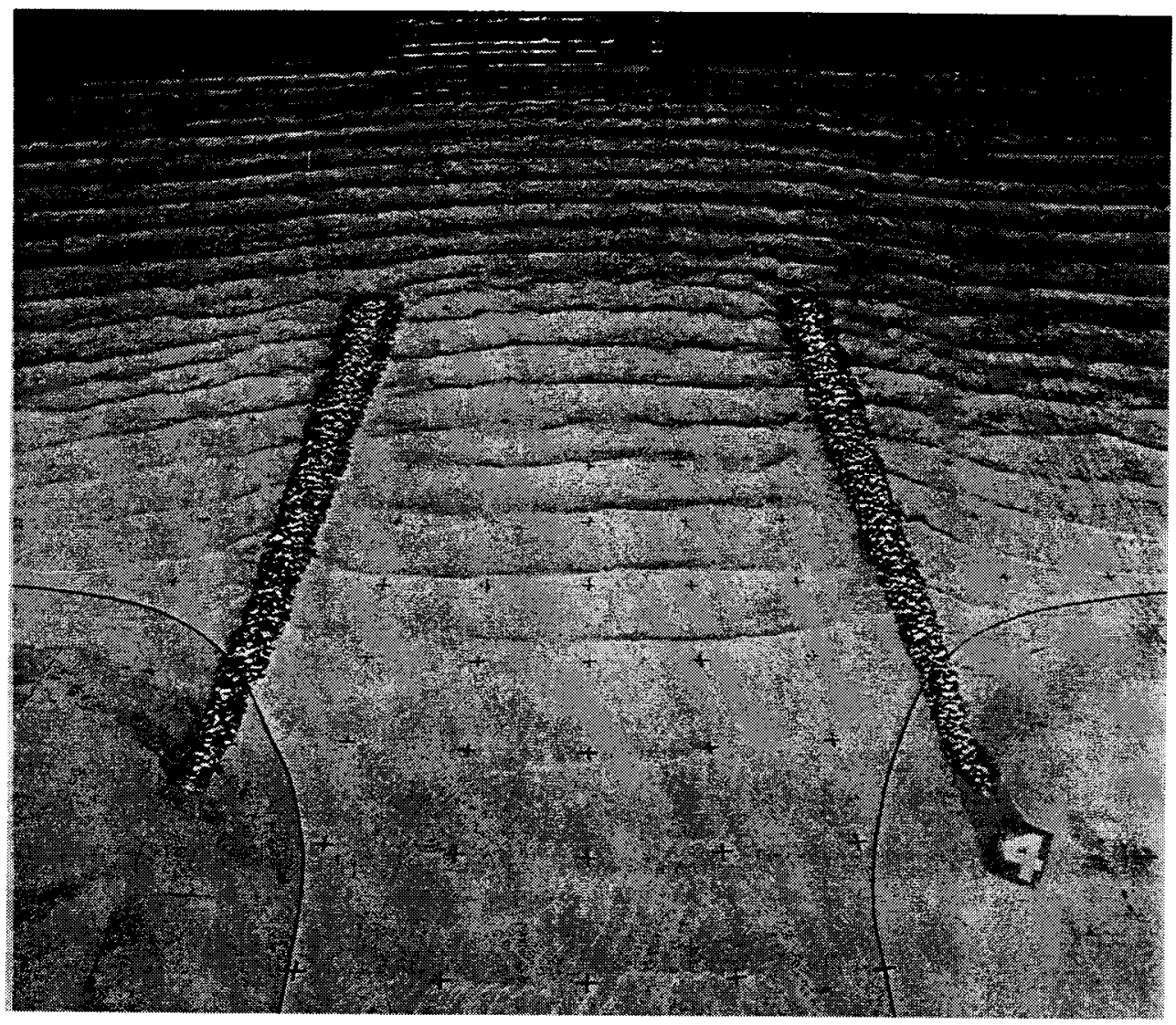

Photo 5. Wave height: $5.5 \mathrm{~cm}$, wave period $0.7 \mathrm{sec}$, ebb current: $12 \mathrm{~cm} / \mathrm{sec}$ 


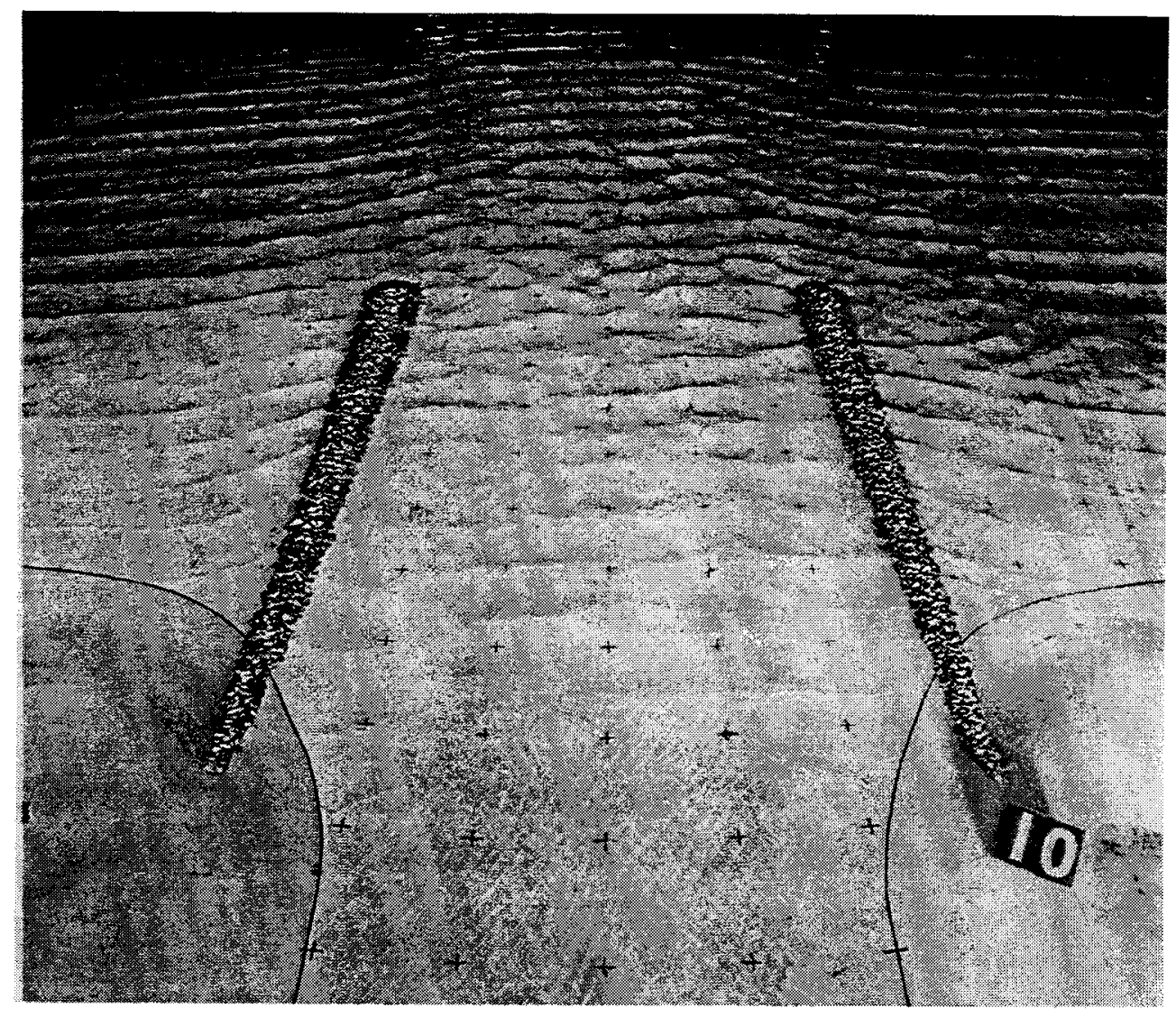

Photo 6. Wave height: $5.5 \mathrm{~cm}$, wave period: $0.7 \mathrm{sec}$, ebb current: $24 \mathrm{~cm} / \mathrm{sec}$ 


\section{Appendix A \\ Data Tables}

\begin{tabular}{|c|c|c|c|c|}
\hline \multicolumn{5}{|c|}{$\begin{array}{l}\text { Table A1 } \\
\text { Wave and Current Data }\end{array}$} \\
\hline Run & Gauge & $H_{m o}(\mathrm{~cm})$ & $f_{p}(\mathrm{~Hz})$ & $U(\mathrm{~cm} / \mathrm{s})$ \\
\hline 1 & Avg of $1-7$ & 5.64 & 0.71 & 0 \\
\hline 1 & 8 & 5.00 & 0.71 & 0 \\
\hline 1 & 9 & 5.42 & 0.71 & 0 \\
\hline 1 & 10 & 5.05 & 0.71 & 0 \\
\hline 1 & 11 & 5.03 & 0.71 & 0 \\
\hline 1 & 12 & 4.80 & 0.71 & 0 \\
\hline 1 & 13 & 5.59 & 0.71 & 0 \\
\hline 2 & Avg of 1.7 & 3.77 & 0.71 & 0 \\
\hline 2 & 8 & 3.42 & 0.71 & 0 \\
\hline 2 & 9 & 3.87 & 0.71 & 0 \\
\hline 2 & 10 & 3.83 & 0.71 & 0 \\
\hline 2 & 11 & 3.91 & 0.71 & 0 \\
\hline 2 & 12 & 3.82 & 0.71 & 0 \\
\hline 2 & 13 & 3.70 & 0.71 & 0 \\
\hline 3 & Avg of 1-7 & 4.32 & 1.37 & 0 \\
\hline 3 & 8 & 3.81 & 1.37 & 0 \\
\hline 3 & 9 & 4.13 & 1.33 & 0 \\
\hline 3 & 10 & 4.01 & 1.41 & 0 \\
\hline 3 & 11 & 4.09 & 1.33 & 0 \\
\hline 3 & 12 & 4.00 & 1.33 & 0 \\
\hline
\end{tabular}




\begin{tabular}{|c|c|c|c|c|}
\hline Run & Gauge & $H_{m o}(\mathrm{~cm})$ & $f_{p}(\mathrm{~Hz})$ & $U(\mathrm{~cm} / \mathrm{s})$ \\
\hline 3 & 13 & 5.15 & 1.41 & 0 \\
\hline 4 & Avg of $1-7$ & 3.25 & 1.37 & 0 \\
\hline 4 & 8 & 2.88 & 1.41 & 0 \\
\hline 4 & 9 & 3.13 & 1.41 & 0 \\
\hline 4 & 10 & 3.12 & 1.37 & 0 \\
\hline 4 & 11 & 3.20 & 1.37 & 0 \\
\hline 4 & 12 & 3.20 & 1.41 & 0 \\
\hline 4 & 13 & 3.71 & 1.41 & 0 \\
\hline 5 & Avg of $1-7$ & 6.32 & 0.71 & 0 \\
\hline 5 & 8 & 5.60 & 0.71 & 9.65 \\
\hline 5 & 9 & 5.92 & 0.71 & 10.35 \\
\hline 5 & 10 & 5.22 & 0.71 & 11.65 \\
\hline 5 & 11 & 5.27 & 0.71 & 12.08 \\
\hline 5 & 12 & 4.84 & 0.71 & 12.43 \\
\hline 5 & 13 & 5.77 & 0.78 & 12.95 \\
\hline 6 & Avg of $1-7$ & 5.54 & 0.75 & 0 \\
\hline 6 & 8 & 4.94 & 0.75 & 9.61 \\
\hline 6 & 9 & 5.30 & 0.71 & 10.60 \\
\hline 6 & 10 & 4.91 & 0.71 & 11.97 \\
\hline 6 & 11 & 4.95 & 0.71 & 12.20 \\
\hline 6 & 12 & 4.69 & 0.71 & 12.56 \\
\hline 6 & 13 & 4.08 & 0.78 & 13.07 \\
\hline 7 & Avg of 1.7 & 5.25 & 1.37 & 0 \\
\hline 7 & 8 & 4.72 & 1.33 & 9.54 \\
\hline 7 & 9 & 4.96 & 1.33 & 10.09 \\
\hline 7 & 10 & 4.52 & 1.25 & 11.36 \\
\hline 7 & 11 & 4.74 & 1.25 & 11.96 \\
\hline 7 & 12 & 4.32 & 1.29 & 12.40 \\
\hline 7 & 13 & 5.30 & 1.41 & 12.94 \\
\hline
\end{tabular}




\begin{tabular}{|c|c|c|c|c|}
\hline Run & Gauge & $H_{m o}(\mathrm{~cm})$ & $f_{p}(H z)$ & $U(\mathrm{~cm} / \mathrm{s})$ \\
\hline 8 & Avg of $1-7$ & 4.90 & 1.37 & 0 \\
\hline 8 & 8 & 4.36 & 1.37 & 9.27 \\
\hline 8 & 9 & 4.62 & 1.33 & 9.70 \\
\hline 8 & 10 & 4.17 & 1.33 & 10.93 \\
\hline 8 & 11 & 4.18 & 1.33 & 11.66 \\
\hline 8 & 12 & 3.76 & 1.33 & 12.15 \\
\hline 8 & 13 & 3.92 & 1.45 & 12.72 \\
\hline 9 & Avg of $1-7$ & 7.18 & 0.71 & 0 \\
\hline 9 & 8 & 6.10 & 0.71 & 19.49 \\
\hline 9 & 9 & 5.92 & 0.71 & 20.59 \\
\hline 9 & 10 & 5.26 & 0.71 & 22.51 \\
\hline 9 & 11 & 5.01 & 0.71 & 22.83 \\
\hline 9 & 12 & 4.61 & 0.82 & 22.85 \\
\hline 9 & 13 & 5.97 & 0.78 & 23.38 \\
\hline 10 & Avg of 1.7 & 6.27 & 0.71 & 0 \\
\hline 10 & 8 & 5.43 & 0.71 & 18.45 \\
\hline 10 & 9 & 5.40 & 0.71 & 20.06 \\
\hline 10 & 10 & 4.63 & 0.71 & 22.43 \\
\hline 10 & 11 & 4.46 & 0.71 & 22.63 \\
\hline 10 & 12 & 3.99 & 0.75 & 23.09 \\
\hline 10 & 13 & 4.61 & 0.78 & 24.12 \\
\hline 11 & Avg of $1-7$ & 6.23 & 1.22 & 0 \\
\hline 11 & 8 & 5.13 & 1.22 & 19.02 \\
\hline 11 & 9 & 4.77 & 1.22 & 20.19 \\
\hline 11 & 10 & 3.83 & 1.22 & 22.30 \\
\hline 11 & 11 & 3.45 & 1.18 & 22.76 \\
\hline 11 & 12 & 3.15 & 1.18 & 23.21 \\
\hline 11 & 13 & 5.51 & 1.37 & 24.14 \\
\hline
\end{tabular}




\begin{tabular}{|c|c|c|c|c|}
\hline Run & Gauge & $H_{m o}(\mathrm{~cm})$ & $f_{p}(H z)$ & $U(\mathrm{~cm} / \mathrm{s})$ \\
\hline 12 & Avg of $1-7$ & 4.65 & 1.25 & 0 \\
\hline 12 & 8 & 4.17 & 1.22 & 18.80 \\
\hline 12 & 9 & 4.26 & 1.22 & 20.09 \\
\hline 12 & 10 & 3.65 & 1.25 & 22.01 \\
\hline 12 & 11 & 2.93 & 1.22 & 22.09 \\
\hline 12 & 12 & 2.58 & 1.18 & 22.44 \\
\hline 12 & 13 & 4.16 & 1.37 & 23.34 \\
\hline
\end{tabular}




\begin{tabular}{||l|l|l|l|l||}
\hline \multicolumn{2}{|l}{$\begin{array}{l}\text { Table A2 } \\
\text { Still-Water Depths at Gauges }\end{array}$} \\
\hline \multirow{2}{*}{ Gauge No. } & \multirow{2}{*}{ Type Gauge } & \multicolumn{3}{|l|}{ Still-Water Depth, cm } \\
\cline { 2 - 5 } & & Left & \multicolumn{1}{l|}{ Center } & Right \\
\hline 1 & Current meter & 12.2 & 12.2 & 12.2 \\
\hline 2 & Current meter & 10.4 & 10.3 & 10.3 \\
\hline 3 & Current meter & 8.5 & 8.8 & 8.8 \\
\hline 4 & Current meter & 8.8 & 9.1 & 9.1 \\
\hline 5 & Current meter & 9.1 & 8.8 & 9.1 \\
\hline 8 & Wave & 12.5 & 12.8 & 13.1 \\
\hline 9 & Wave & 11.3 & 11.3 & 11.3 \\
\hline 10 & Wave & 9.5 & 9.5 & 9.1 \\
\hline 11 & Wave & 8.8 & 8.8 & 9.1 \\
\hline 12 & Wave & 8.8 & 9.1 & 9.1 \\
\hline 13 & Wave & 9.1 & 9.1 & 9.1 \\
\hline Note: Left, center, and right are gauge lines looking seaward from inlet. & \\
\hline
\end{tabular}




\section{Appendix B Spectra Plots}



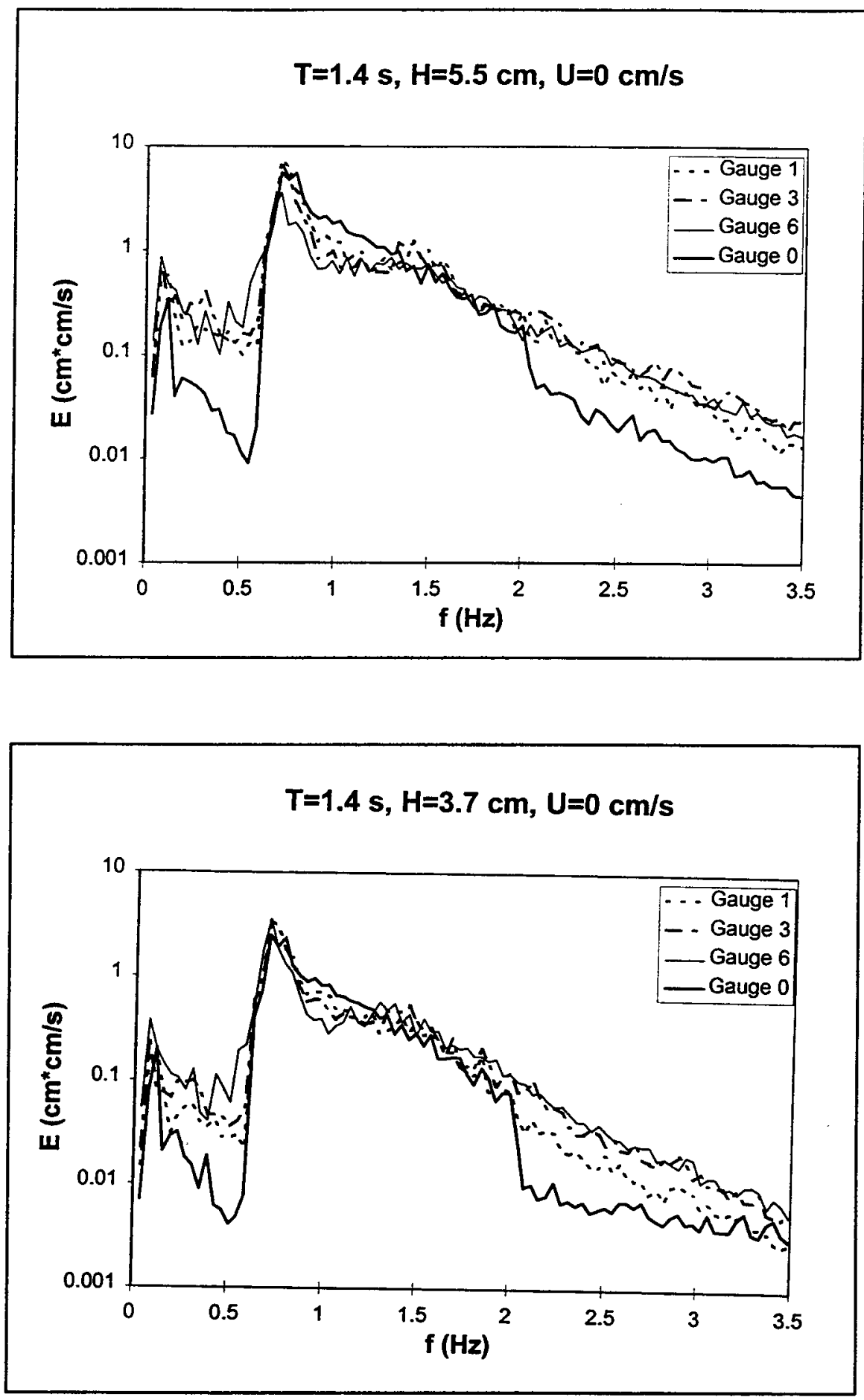
$T=0.7 \mathrm{~s}, H=5.5 \mathrm{~cm}, U=0 \mathrm{~cm} / \mathrm{s}$

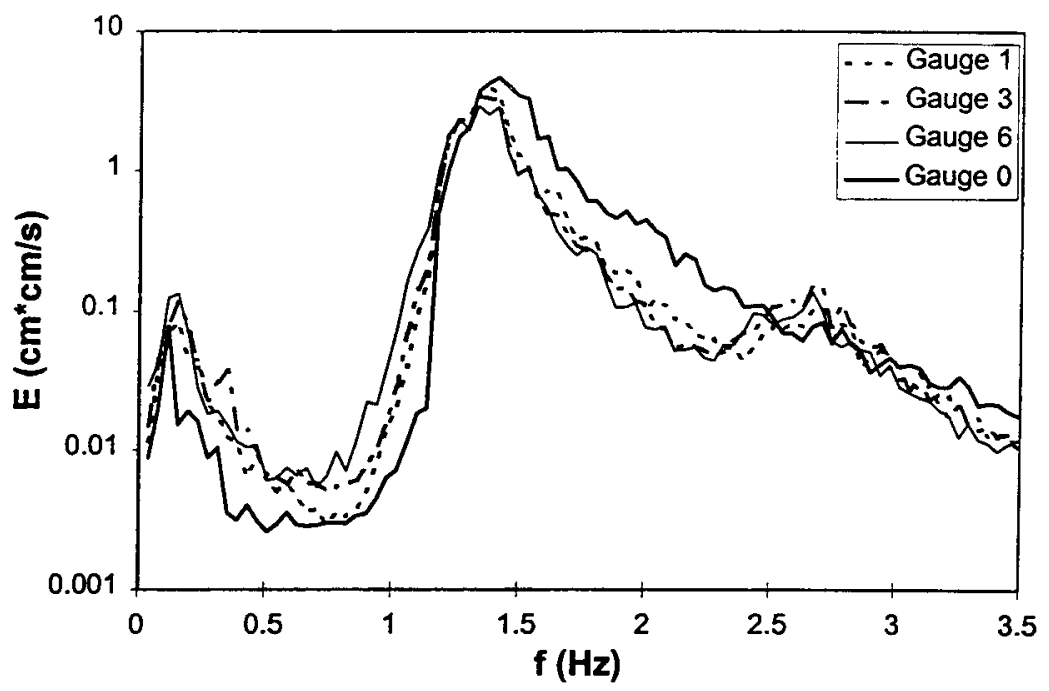

$T=0.7 \mathrm{~s}, H=3.7 \mathrm{~cm}, U=0 \mathrm{~cm} / \mathrm{s}$

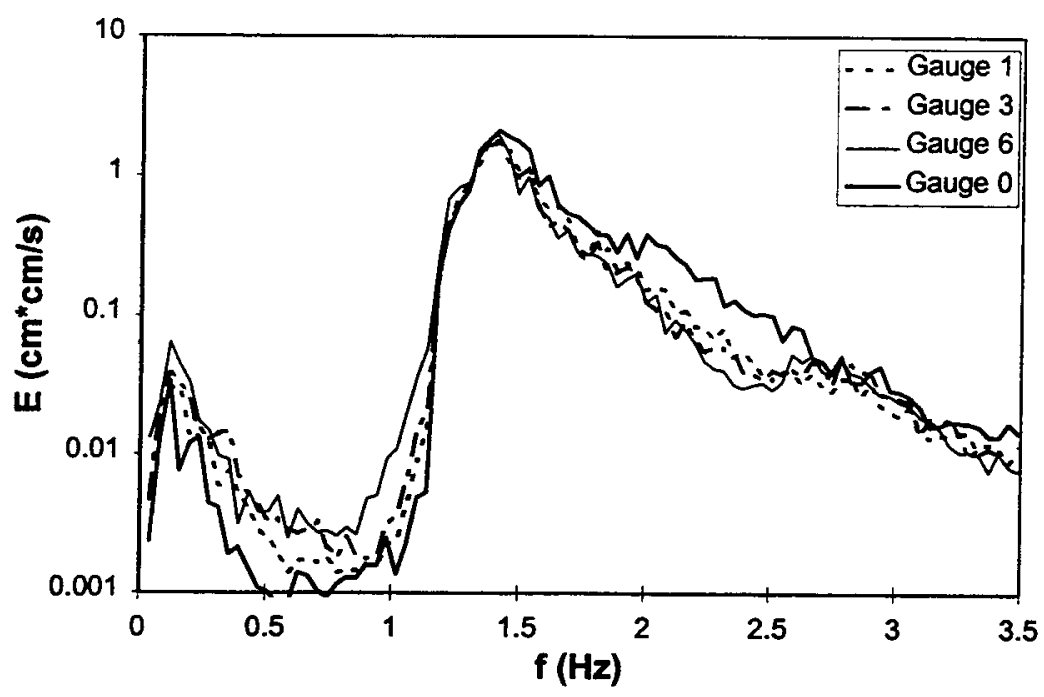



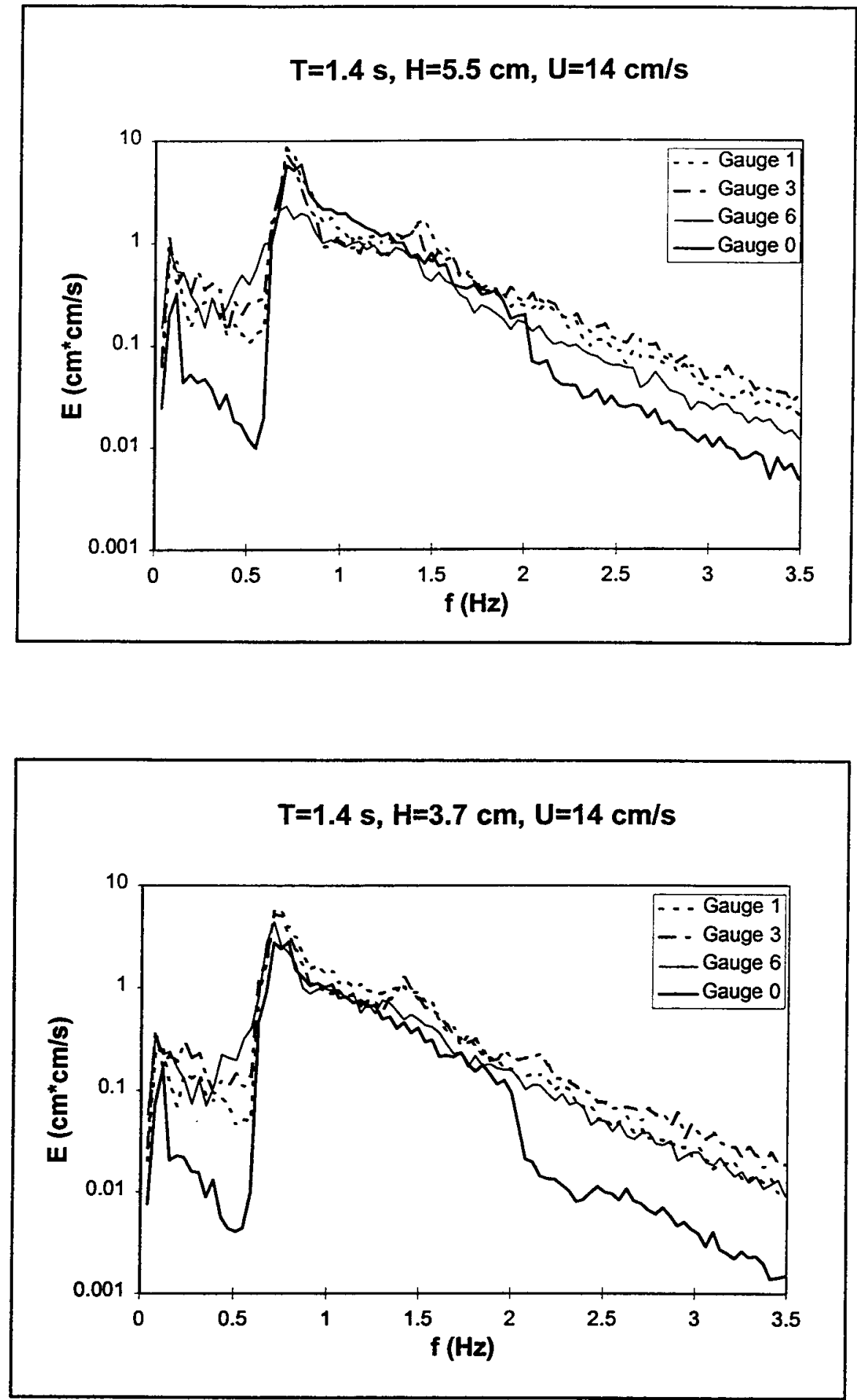

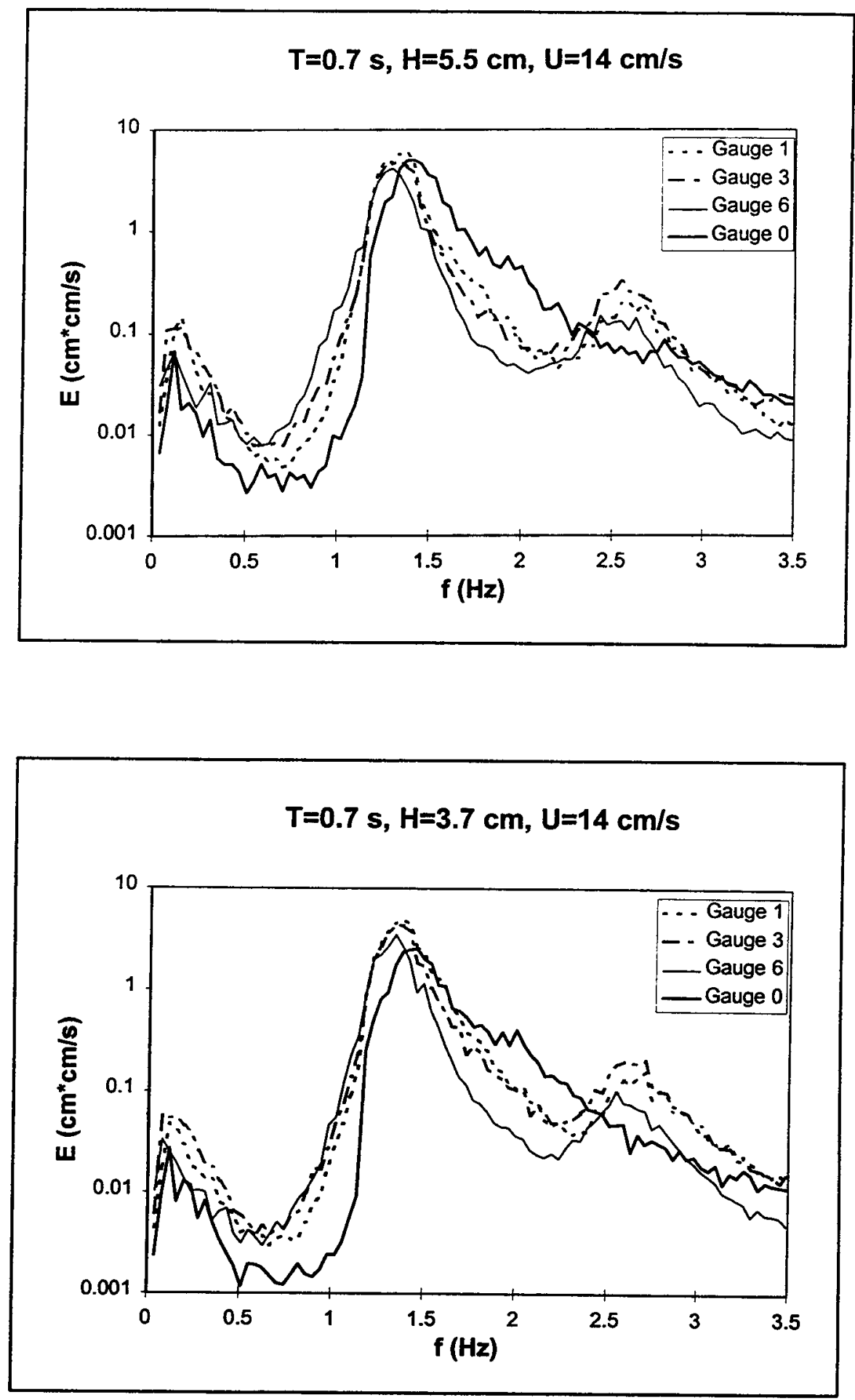

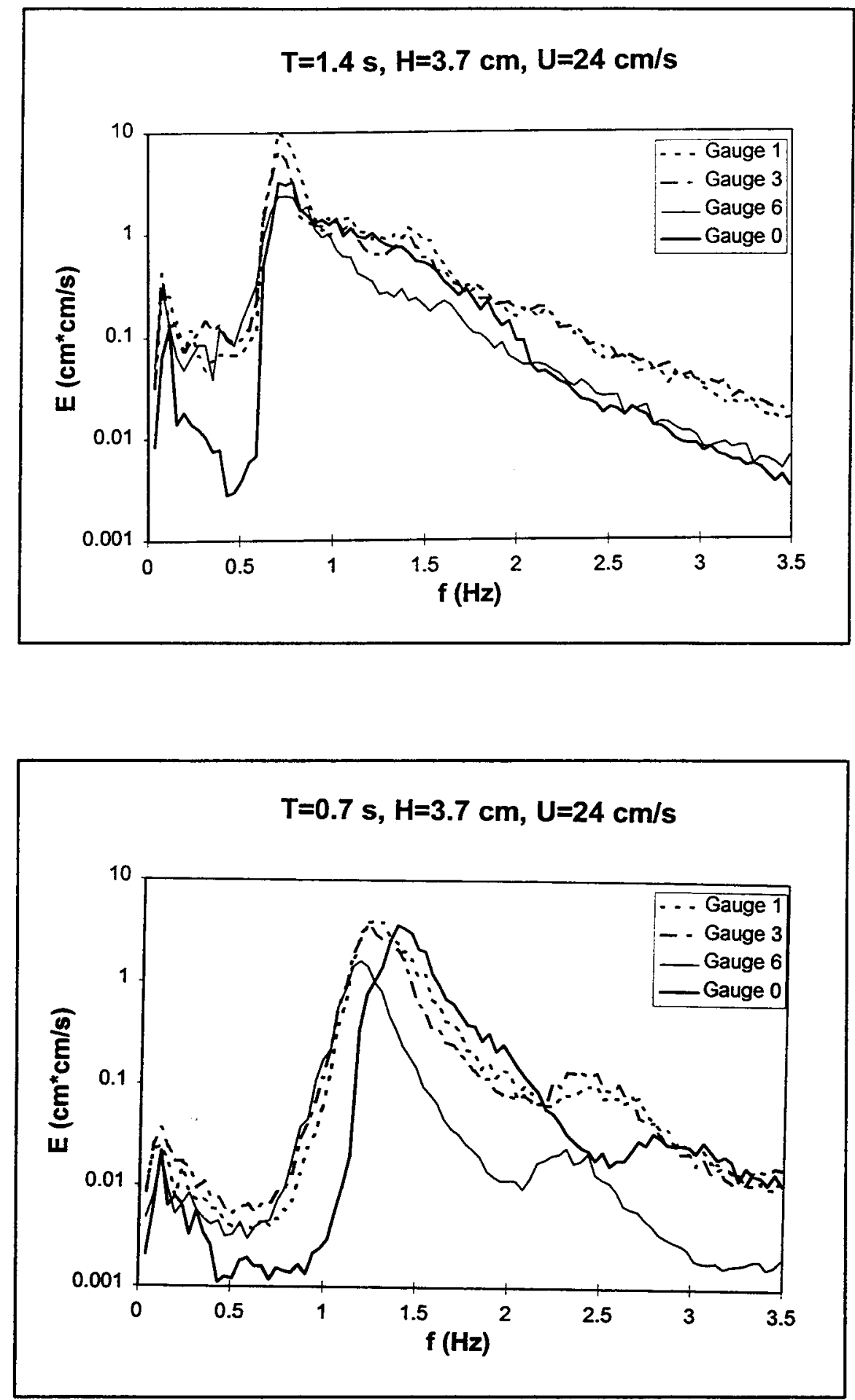


\section{Appendix C Notation}

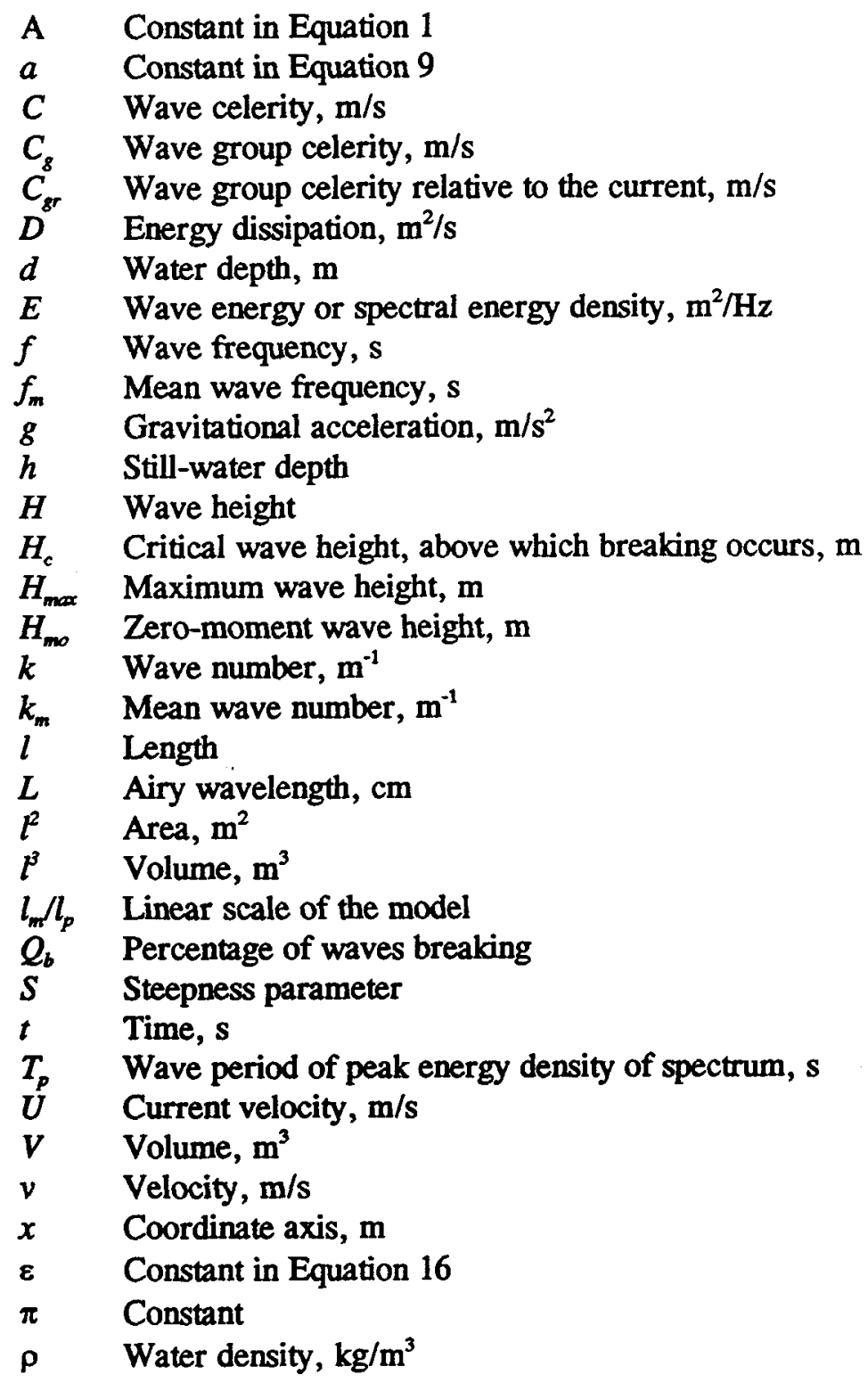


$\omega \quad$ Angular frequency, $s^{-1}$

$\omega_{\mathrm{r}} \quad$ Angular frequency relative to the current, $\mathrm{s}^{-1}$

$\omega_{\mathrm{m}} \quad$ Mean angular frequency 
Public reporting burden for this collection of information is estimated to average 1 hour per response, including the time for reviewing instructions, searching existing data sources, gathering and maintaining the data needed, and completing and reviewing the collection of information. Send comments regarding this burden estimate or any other aspect of this collection of information, including suggestions for reducing this burden, to Washington Headquarters Services, Directorale for information Operations and Reports, 1215 Jefferson Davis Highway, Sute 1204. Artington, VA 22202-4302, and to the Office of Management and Budget, Paperwork Reduction Project (0704-0188), Wastington, DC 20503.
1. AGENCY USE ONLY (Leave blank)
2 REPORT DATE
November 1998
3. REPORT TYPE AND DATES COVERED
Final report

4. TILE AND SUBTILE

Wave Breaking on a Current at an Idealized Inlet; Coastal Inlets Research

Program, Inlet Laboratory Investigations

6. AUTHOR(S)

Jane M. Smith, William C. Seabergh, Gordon S. Harkins, Michael J. Briggs

7. PERforming ORganization NAME(S) AND AdDRESS(ES)

U.S. Army Engineer Waterways Experiment Station

3909 Halls Ferry Road, Vicksburg, MS 39180-6199

8. PERforming ORganization REPORT NUMBER

Technical Report CHL-98-31

9. SPONSORAMCMUONTORING AGENCY MAME(S) AND ADDRESS(ES)

U.S. Army Corps of Engineers

10. SPONSOAWGMONTORHG

Washington, DC 20314-1000

AGENCY REPOAT NUMBER

11. SUPPLEMENTARY NOTES

Available from National Technical Information Service, 5285 Port Royal Road, Springfield, VA 22161.

12a. DISTRIBUTOOVAVALABUTY STATEMENT

12b. DISTRIBUTION CODE

Approved for public release; distribution is unlimited.

13. ABSTRACT (Maximum 200 words)

Laboratory measurements of wave shoaling and breaking on an ebb current were made in an idealized inlet in a wave basin. The experiment arrangement, procedures, and data analysis are described. The wave and ebb current measurements showed increased shoaling and breaking (compared to no current, shifting of the spectral peak to lower frequencies, and energy dissipation concentrated at the spectral peak and higher frequencies). The measurements were used to evaluate and develop formulations of wave dissipation on a current for application to a spectral wave model. Whitecapping dissipation formulations underpredicted breaking on a current in shallow water, whereas the bore-based wave dissipation relationship of Battjes and Janssen and a relationship developed in this study provided good estimates of wave-height decay on an ebb current. Tables of the wave and current parameters are provided as an appendix.

14. SUBJECT TERISS

Coastal Inlet

Ebb currents

Laboratory measurements
Wave breaking

Wave dissipation

\begin{tabular}{l|l}
\hline $\begin{array}{l}\text { 17. SECURTY CLASSIFICATION } \\
\text { OF REPOFT }\end{array}$ & 18. SECUPTY CLASSIFICATION \\
ONCLASSIFIED & UNCL PAGE \\
UNCLASSIFIED
\end{tabular}

NSN 7540-01-280-5500
15. MUMBER OF PAGES

57

16. PRICE CODE

\begin{tabular}{|l|l|}
\hline & $\begin{array}{l}\text { 15. MUMBER OF PAGES } \\
57\end{array}$ \\
\hline & 16. PRICE CODE \\
\hline $\begin{array}{l}\text { 19. SECURITY CLASSHFCATION } \\
\text { OF ABSTRACT }\end{array}$ & 20. LMITATION OF ABSTRACT \\
\hline
\end{tabular}

Standard Form 298 (Rev. 2-89) Prescribed by ANSI Sid. Z39-18 298-102 